\title{
REVIEW
}

\section{On the added value of multi-scale modeling of concrete}

\author{
Jiaolong ZHANG ${ }^{\text {a }}$, Eva BINDER ${ }^{\text {b\# }}$, Hui WANG ${ }^{\mathrm{c} \#}$, Mehdi AMINBAGHAI ${ }^{\mathrm{d}}$, Bernhard LA PICHLER ${ }^{\mathrm{d}}$, Yong \\ YUAN $^{\mathrm{a}}$, Herbert A MANG ${ }^{\mathrm{a}, \mathbf{d}^{*}}$ \\ ${ }^{a}$ College of Civil Engineering, Tongji University, Shanghai 200092, China \\ ${ }^{b}$ Department of Building Technology, Linnaeus University, Växjö 35195, Sweden \\ ${ }^{c}$ School of Naval Architecture, Ocean and Civil Engineering, Shanghai Jiao Tong University, Shanghai 200240, China \\ ${ }^{d}$ Institute for Mechanics of Materials and Structures, TU Wien, Vienna 1040, Austria \\ *Corresponding author. E-mail: Herbert.mang@tuwien.ac.at \\ \#\#qual contributions from the marked authors
}

C The Author(s) 2022. This article is published with open access at link.springer.com and journal.hep.com.cn

\begin{abstract}
This review of the added value of multi-scale modeling of concrete is based on three representative examples. The first one is concerned with the analysis of experimental data, taken from four high-dynamic tests. The structural nature of the high-dynamic strength increase can be explained by using a multi-scale model. It accounts for the microstructure of the specimens. The second example refers to multi-scale thermoelastic analysis of concrete pavements, subjected to solar heating. A sensitivity analysis with respect to the internal relative humidity $(R H)$ of concrete has underlined the great importance of the $R H$ for an assessment of the risk of microcracking of concrete. The third example deals with multi-scale structural analysis of a real-scale test of a segmental tunnel ring. It has turned out that multi-scale modeling of concrete enables more reliable predictions of crack opening displacements in tunnel segments than macroscopic models taken from codes of practice. Overall, it is concluded that multi-scale models have indeed a significant added value. However, its degree varies with these examples. In any case, it can be assessed by means of a comparison of the results from three sources, namely, multi-scale structural analysis, conventional structural analysis, and experiments.
\end{abstract}

KEYWORDS experiments, multi-scale analysis, conventional structural analysis, concrete, reinforced concrete

\section{Introduction}

The present paper is an extended version of an invited lecture delivered online by the last author at the International Conference of Frontiers of Structural and Civil Engineering, on October 20, 2020, in Shanghai, China. The research results were obtained in the framework of an international research project. The participants of this project are from TU Wien, Vienna, Austria, and Tongji University, Shanghai, China. The thematic focus is set on reviewing the added value created by means of multi-scale modeling of concrete. Such a review is a challenging task, not least because of the existence of numerous multi-scale models. They account for chemical, thermal, hygral, poromechanical,

Article history: Received Jul 24, 2021; Accepted Oct 28, 2021 and/or other information from microstructural scales, and they are either based on a detailed discretization of the microstructure of concrete, see, e.g., Refs. [1-3], or on mean-field methods focused on key features of the microstructure, see, e.g., Refs. [4-6].

A review of the added value of multi-scale analysis must be based on non-trivial examples. Admittedly, the selected examples can always be criticized for not being sufficiently representative. Overemphasis on such a criticism may trigger knock-out arguments. However, this would not be a scientific attitude, as philosophically corroborated by Popper in his theory of falsifications in science [7]. According to this theory, the validation of any scientific theory is always incomplete, because, at least theoretically, there are infinitely many possibilities of trying to falsify the theory. This is a reasonable argument for promoting exemplary validations, because 
the more serious attempts of falsification a theory survives, the more it is corroborated [7]. This enhances the usefulness of the present paper.

In the run-up to the aforementioned Austro-Chinese research project, the added value of multi-scale modeling of concrete was demonstrated, e.g., in the context of predicting the early-age evolutions of mechanical properties of concrete [8,9] and by applying multi-scale models to structural analysis of shotcrete linings used in the New Austrian Tunneling Method, see Refs. [10,11] and references therein. Therefore, the focus of the present contribution is on mature concrete. In order to provide a comprehensive review of the aforementioned added value of multiscale modeling of concrete, one microstructural example and two macrostructural examples were selected. They refer to three different areas: material science, road engineering, and tunnel engineering, as explained in more detail in the following three paragraphs.

The first example (Section 2) refers to the question whether high-dynamic strength values are a material or structural property. Notably, material properties are independent of the size and shape of the tested specimens. In this work, material models are taken from the literature and the fib Model Code. They are compared with the multi-scale model of Fischer et al. [12] and Binder et al. [13]. This model suggests that the high-dynamic strength increase is of structural nature, because it depends on the size of the tested specimen. The assessment of the added value resulting from multi-scale modeling is based on the application of the selected models to the analysis of experimental data, taken from four high-dynamic strength testing campaigns.

The second example (Section 3) refers to the macrostructural problem of thermal stresses of pavement plates subjected to solar heating. Multi-scale modeling includes both bottom-up homogenization of the thermoelastic properties of concrete and top-down quantification of the stresses of the constituents of concrete, namely, coarse aggregates, fine aggregates, and cement paste. The added value resulting from multi-scale modeling is assessed by performing a sensitivity analysis regarding the internal relative humidity $(R H)$ of concrete. The motivation for this analysis is that he thermal expansion coefficient of the cement paste is a bell-shaped function of the $R H$. Consequently, thermal stresses depend, in a nontrivial fashion, on the $R H$.

The third example (Section 4) refers to the macrostructural problem of bending-induced tensile cracking of segmental tunnel linings. The latter were subjected to point loads which simulate the ground pressure. A real-scale bearing capacity test of a segmental tunnel ring is analyzed, based on four different models describing the strain-stress relation of concrete in tension. Three macroscopic models are taken from codes of practice. The fourth model is a multi-scale model taken from the Ph.D. desertation of Hlobil [14]. The added value resulting from multi-scale modeling is assessed by means of a comparison of model predictions and experimental data, focusing on values of the external loading at which tensile cracking of the tunnel segments started in the real-scale test and on measured crack opening displacements close to the bearing capacity of the structure.

In Section 5, conclusions are drawn, based on the results obtained from three different examples.

\section{Multiscale analysis of high-dynamic strengthening - a structural problem}

\subsection{Experimental evidence}

Experimental data from the literature have shown increasing ultimate stresses in uniaxial dynamic compression tests of cementitious materials when the strain rate increases. Data from experimental testing campaigns on concrete, mortar, and cement paste specimens, considered in this work, are summarized in Table 1. All tests were done on dry specimens made of concrete, mortar, or cement paste. Diameters and axial lengths of the cylindrical specimens are denoted as $d$ and $\ell$, respectively. Restriction to compression tests suggests treating both the stress and the strain rate as positive quantities in case of compression.

Up to now, it has not been clear why $f_{\text {ult }}$ depends on the strain rate. Different attempts of explanations are found in the literature. As for uniaxial compression tests, strainrate-dependent material properties, e.g., in Refs. [17-19], internal confinement leading to triaxial stress states, e.g., in Refs. [20-22], structural effects, e.g., in Refs. $[12,13,23]$, or combinations of these assumptions, e.g., in Refs. [24,25], are used to explain the strain-rate dependence of $f_{\text {ult }}$. In order to compare different approaches and materials, the increase of the ultimate stress at high strain rates is usually expressed by the dynamic increase factor $(D I F)$ of the ultimate stress. In the literature, it is given as

$$
D I F=\frac{f_{\text {ult }}}{f_{\text {sta }}},
$$

where $f_{\text {ult }}$ stands for the ultimate stress, obtained from high-dynamic tests, and $f_{\text {sta }}$ denotes the stress reached in a quasi-static test, accordingly referred to as the quasi-static strength. Many analytical expressions for the DIF in compression were developed, based on empirical fitting of data from experiments or models. A selected collection from expressions published in the years 1990-2015 in the open literature can be found in Ref. [24].

\subsection{Various models}

In this work, the interest lies in existing analytical 
Table 1 Selected experimental data from high-dynamic compression tests in the literature

\begin{tabular}{|c|c|c|c|c|c|c|c|}
\hline \multirow{2}{*}{\multicolumn{2}{|c|}{$\begin{array}{l}\text { Fischer et al. [12] tested cement } \\
\text { paste samples ( } 6 \text { months old) }\end{array}$}} & \multirow{2}{*}{\multicolumn{2}{|c|}{$\begin{array}{l}\text { Kühn et al. [15] tested concrete } \\
\text { samples (5 months old) }\end{array}$}} & \multicolumn{4}{|c|}{ Zhang et al. [16] tested mortar samples with two different sizes } \\
\hline & & & & \multicolumn{2}{|c|}{ small specimens } & \multicolumn{2}{|c|}{ large specimens } \\
\hline$f_{\text {ult }}(\mathrm{MPa})$ & $\dot{\varepsilon}(1 / \mathrm{s})$ & $f_{\text {ult }}(\mathrm{MPa})$ & $\dot{\varepsilon}(1 / \mathrm{s})$ & $f_{\text {ult }}(\mathrm{MPa})$ & $\dot{\varepsilon}(1 / \mathrm{s})$ & $f_{\text {ult }}(\mathrm{MPa})$ & $\dot{\varepsilon}(1 / \mathrm{s})$ \\
\hline 74.15 & 700 & 95.1 & 136.6 & 70.66 & 49.46 & 64.45 & 37.01 \\
\hline 42.01 & 200 & 104.2 & 150.1 & 73.82 & 71.01 & 71.22 & 69.67 \\
\hline 74.41 & 500 & 119.2 & 185.5 & 74.75 & 85.09 & 71.47 & 76.68 \\
\hline 48.6 & 500 & 125.7 & 190 & 75.11 & 130.74 & 75.02 & 56.43 \\
\hline 65.4 & 500 & 142.5 & 202.7 & 75.61 & 153.16 & 72.13 & 89.38 \\
\hline 114.26 & 500 & - & - & 79.67 & 183.52 & 76.01 & 126.2 \\
\hline 132.73 & 1900 & - & - & 81.66 & 219.90 & 77.00 & 152.86 \\
\hline 164.39 & 2100 & - & - & 86.57 & 205.48 & 79.14 & 126.2 \\
\hline 156.36 & 2100 & - & - & 90.43 & 295.02 & 82.03 & 165.04 \\
\hline 133.73 & 2100 & - & - & 96.52 & 337.87 & 88.8 & 192.39 \\
\hline 152.64 & 2100 & - & - & 98.16 & 345.6 & 93.34 & 165.04 \\
\hline 143.78 & 1900 & - & - & 99.45 & 322.94 & 93.75 & 228.61 \\
\hline- & - & - & - & 101.67 & 330.32 & 98.62 & 261.43 \\
\hline - & - & - & - & 109.04 & 453.30 & - & - \\
\hline
\end{tabular}

Notes: Fischer et al. [12]: $\ell=6.63 \mathrm{~mm}, d=10.1 \mathrm{~mm}, f_{\text {sta }}=48.2 \mathrm{MPa}, E=14.2 \mathrm{GPa}, v=0.29, \rho=1593 \mathrm{~kg} / \mathrm{m}^{3} ; \mathrm{Kühn} \mathrm{et} \mathrm{al.}[15]: \ell=80.0 \mathrm{~mm}, d=50.0 \mathrm{~mm}, f_{\text {sta }}=$ $25.1 \mathrm{MPa}, E=32.0 \mathrm{GPa}, v=0.20, \rho=2400 \mathrm{~kg} / \mathrm{m}^{3}$; Zhang et al. [16], small specimens: $\ell=18.0 \mathrm{~mm}, d=37.0 \mathrm{~mm}, f_{\text {sta }}=51.0 \mathrm{MPa}, E=23.1 \mathrm{GPa}, v=0.19$, $\rho=2116 \mathrm{~kg} / \mathrm{m}^{3}$; Zhang et al. [16], large specimens: $\ell=25.0 \mathrm{~mm}, d=50.0 \mathrm{~mm}, f_{\mathrm{sta}}=51.0 \mathrm{MPa}, E=23.1 \mathrm{GPa}, v=0.19, \rho=2116 \mathrm{~kg} / \mathrm{m}^{3}$.

expressions that can be applied to different experimental testing campaigns by fitting of parameters. The selected five expressions show the wide range of possible modeling origins and mathematical expressions for modeling of the strain-rate effect of ultimate stresses in compression tests, summarized in the following.

1) Tang et al. [26] investigated the strain-rate effect of concrete in compression with the help of a SplitHopkinson Pressure Bar. They identified small confinement stresses which were not responsible for the enhancement of the ultimate stress at higher loading rates. They proposed a linear regression model, given as

$$
D I F=\frac{C+D \dot{\varepsilon}}{f_{\text {sta }}}, \text { for value of } D I F>1.0,
$$

where the two fitting parameters, $C$ and $D$, were identified for individual test series.

2) Gebbeken and Greulich [27] assumed a limit of the increase of the ultimate stress at high strain rates. They recommended a hyperbolic function for the definition of this limit, given as

$$
D I F=\frac{W_{y}}{f_{\text {sta }}}\left\{\tanh \left[\left(\log \left(\frac{\dot{\varepsilon}}{1.0 \mathrm{~s}^{-1}}\right)-W_{x}\right) S\right]\left(\frac{F_{\mathrm{m}}}{W_{y}}-1\right)+1\right\},
$$

where the parameter $F_{\mathrm{m}}$ denotes the ultimate stress at a theoretical strain rate equal to infinity. The parameters $S$, $W_{x}$ and $W_{y}$ define the shape of the model curve, with $W_{x}$ and $W_{y}$ denoting the location of the point of inflection.
The four parameters can be adjusted to individual test series.

3) Brara and Klepaczko [28] used a time-dependent failure criterion, based on the stress-dependent activation energy and on micro-crack shielding during the cracking process. For short loading pulses, this resulted in

$$
D I F=\frac{1}{f_{\mathrm{sta}}}\left[(1+\xi) t_{\mathrm{C}_{0}} E f_{\mathrm{sta}}^{\xi}\right]^{\frac{1}{\xi+1}} \dot{\boldsymbol{\varepsilon}}^{\frac{1}{\xi+1}},
$$

where $E$ stands for Young's modulus and $t_{\mathrm{C}_{0}}$ denotes the longest period of time until the quasi-static strength is reached in a dynamic test; the parameter $\xi$ is related to the activation energy.

4) $\mathrm{Li}$ et al. [29] investigated the strain-rate effect with the help of a numerical model, including a kinetic friction model. The resulting mathematical expression is a piecewise linear and quadratic expression of the logarithmic strain rate, defined as

$$
\begin{aligned}
& D I F=1+B_{1}\left(\log \left(\frac{\dot{\varepsilon}}{1 \mathrm{~s}^{-1}}\right)+B_{2}\right), \\
& \text { for } \dot{\varepsilon} \leqslant 22.9 \mathrm{~s}^{-1} \text { and } \\
& D I F=B_{3} \log ^{2}\left(\frac{\dot{\varepsilon}}{1 \mathrm{~s}^{-1}}\right)+B_{4} \log \left(\frac{\dot{\varepsilon}}{1 \mathrm{~s}^{-1}}\right)+B_{5},
\end{aligned}
$$$$
\text { for } \dot{\varepsilon}>22.9 \mathrm{~s}^{-1} \text {. }
$$

The factors $B_{1}-B_{5}$ depend on the investigated material and on the size of the specimen. However, this dependence was not quantified. Without using the numerical model, the factors $B_{1}-B_{5}$ can be fitted with the 
help of experimental results.

5) Fischer et al. [12] presented an engineering mechanics approach for modeling the effect of the strainrate on the ultimate stress. The model includes material properties and structural components of the specimen. The expression for the DIF is obtained as

$$
D I F=1+F_{\mathrm{h}} \cdot \ell \cdot \frac{E \dot{\varepsilon}}{f_{\text {sta }}} \sqrt{\frac{2(1+v) \rho}{E}},
$$

where $F_{\mathrm{h}} \cdot \ell$ represents the crack propagation length, expressed as a fraction $F_{\mathrm{h}}$ of the height of the specimen in the loading direction, denoted as $\ell ; E, v$, and $\rho$ stand for Young's modulus, Poisson's ratio, and the mass density, respectively. The model is based on the following assumptions. Cracks start to nucleate as soon as the stress reaches the quasi-static material strength at positions of minimum material resistance. This marks the beginning of the failure process. It ends when the specimen is split into two pieces after a crack has propagated through the whole specimen. The stress in the intact parts of the specimen increases during the failure process. Because the cracks propagate at a characteristic finite speed, the duration of the process is proportional to the size of the specimen. The faster the loading, the larger the stresses gained during crack propagation and the larger the maximum stress sustained by the intact parts, right before the specimen disintegrates into pieces. The described model also suggests that high-dynamic strength testing is associated with significant experimental dispersion, because it is uncertain at which position the first crack will nucleate. If it nucleates in the middle of the specimen, each crack tip has to propagate in half of the cylinder height $\left(F_{\mathrm{h}}=0.5\right)$. However, if it nucleates on a specimen's surface at which the material sample is in contact with the adjacent load plate, the crack has to propagate in the entire cylinder height $\left(F_{\mathrm{h}}=1.0\right)$, for more details see Refs. [12,13].

\subsection{Model application and fitting}

To compare the previously described five models, they are fitted to the experimental data sets of tested cement paste, mortar, and concrete from Table 1. The curve fitting tool from MATLAB [30] is used to adjust all model parameters at once. The obtained parameters are summarized for each model and each experimental data set in Table 2.

Evaluation of the fitted models for a continuous range of strain rates from 10 to $10^{4} \mathrm{~s}^{-1}$ allows plotting of the results from all five models (colored lines) together with the results from the experiments, see Fig. 1(a) for cement paste tests by Fischer et al. [12] (circles), Fig. 1(b) for concrete tests by Kühn et al. [15] (squares), and Figs. 1(c) and 1(d) for tests on different sizes of mortar specimens by Zhang et al. [16] (triangles for smaller specimens and diamonds for larger specimens).

The five plotted model curves for the various experimental data sets show that these curves are the more similar, the more uniform the experimental data are, compare Figs. 1(a) and 1(b). The experimental data from the five tested concretes of Kühn et al. [15] show almost no scatter, and the fitted models are almost identical for the experimentally investigated range of strain rates. However, for smaller strain rates than the experimentally investigated ones, the model curves differ significantly; the model of $\mathrm{Li}$ et al. [29] (orange line) predicts an unreasonable increase of the $D I F$, see Fig. 1(b).

To quantify the performance of the fitted models, the differences between the modeled dynamic increase factors, $D I F_{\text {mod }}$, and the experimentally determined increase factors, $D I F_{\text {exp }}$, are computed by the sum of squared errors (SSE) of the DIF values. Thus,

$$
S S E=\sum_{i=1}^{n}\left(D I F_{\mathrm{exp}, i}-D I F_{\mathrm{mod}, i}\right)^{2},
$$

where $n$ is the number of individual tests in one series. The SSE values for each model and each experimental testing campaign are listed in Table 3. The sums of SSE over the four considered test campaigns for the individual models allow a comparison of the models, based on one error value. The hyperbolic function of Gebbeken and Greulich [27] with four fitting parameters yields an error value of 1.3, and the multi-scale approach of Fischer et al. [12] with one fitting parameter adds up to an error value of 7.3. Overall, the higher the number of fitting parameters, the smaller the calculated error.

The five investigated models can be applied to experimental data sets of various tested cementitious

\begin{tabular}{|c|c|c|c|c|c|c|c|c|c|c|c|c|}
\hline \multirow[t]{2}{*}{ reference } & \multicolumn{2}{|c|}{ Tang et al. [26] } & \multicolumn{4}{|c|}{ Gebbeken and Greulich [27] } & \multicolumn{2}{|c|}{ Brara and Klepaczko [28] } & \multicolumn{3}{|c|}{ Li et al. [29] } & \multirow{2}{*}{$\begin{array}{c}\begin{array}{c}\text { Fischer } \\
\text { et al. [12] }\end{array} \\
F_{\mathrm{h}}\end{array}$} \\
\hline & $C(\mathrm{MPa})$ & $D(\mathrm{MPa} / \mathrm{s})$ & $F_{\mathrm{m}}(\mathrm{MPa})$ & $W_{x}$ & $W_{y}(\mathrm{MPa})$ & $S$ & $t_{\mathrm{C}_{0}}(\mathrm{~s})$ & $\xi$ & $B_{3}$ & $B_{4}$ & $B_{5}$ & \\
\hline Fischer et al. [12] & 72.33 & 0.021 & 143.4 & 2.912 & 96.47 & 5.27 & $9.323 \mathrm{e}-6$ & 1.95 & -1.256 & 9.46 & -14.78 & 0.59 \\
\hline Kühn et al. [15] & 6.986 & 0.638 & 1463 & 1.876 & 30.65 & 0.17 & $2.193 \mathrm{e}-5$ & 0.06 & 56.47 & -241 & 261 & 0.49 \\
\hline $\begin{array}{l}\text { Zhang et al. [16] } \\
\text { (large specimens) }\end{array}$ & 61.11 & 0.142 & 166.2 & 2.6 & 116.1 & 1.95 & $3.296 \mathrm{e}-5$ & 3.73 & 0.5787 & -1.60 & 2.373 & 0.74 \\
\hline $\begin{array}{l}\text { Zhang et al. [16] } \\
\text { (small specimens) }\end{array}$ & 64.11 & 0.099 & 124.8 & 2.527 & 98.5 & 3.32 & $2.839 \mathrm{e}-5$ & 3.69 & 0.684 & -2.01 & 2.608 & 0.74 \\
\hline
\end{tabular}

Table 2 Identified fitting parameters of various models for the investigated experimental test series 


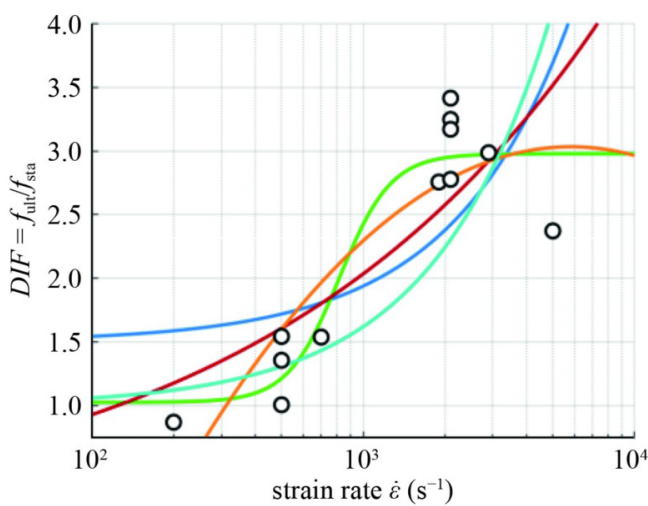

(a)

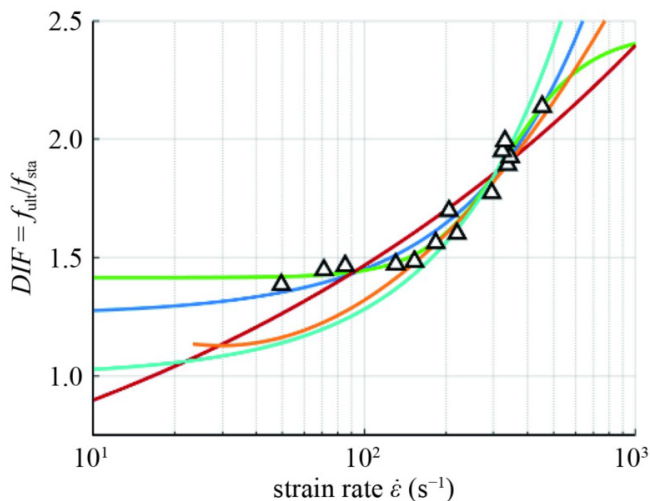

(c)

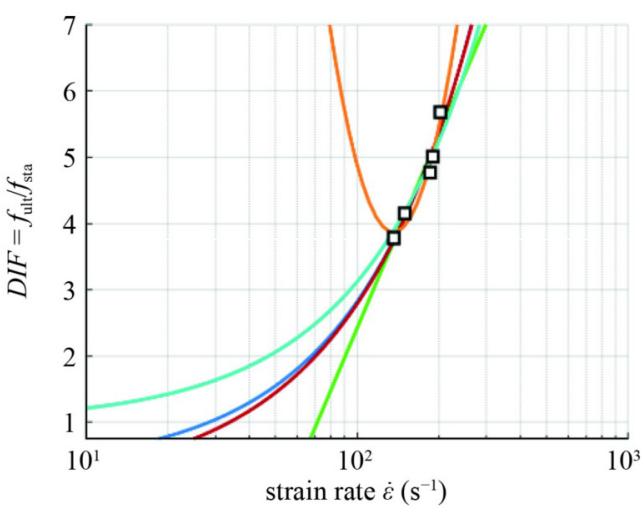

(b)

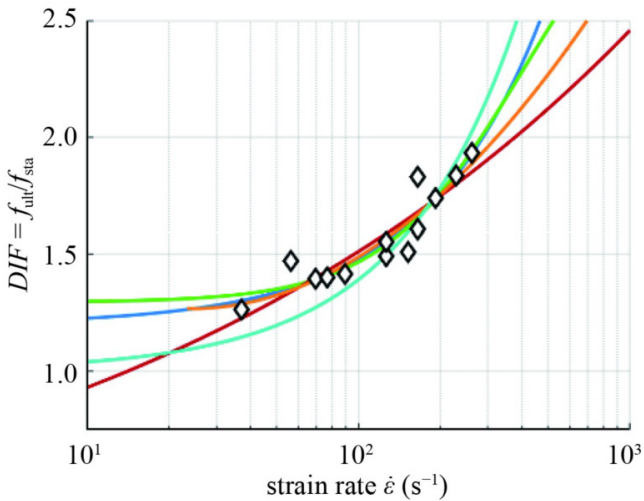

(d)

Fig. 1 Dynamic increase factor of the ultimate stress depending on the strain rate: model of Li et al. [29], in orange, of Gebbeken and Greulich [27], in green, of Brara and Klepaczko [28], in red, of Tang et al. [26], in dark blue, and of Fischer et al. [12], in light blue; Markers represent the experimental results of (a) Fischer et al. [12], (b) Kühn et al. [15], (c) Zhang et al. [16], small specimens, (d) Zhang et al. [16], large specimens.

Table 3 Differences between modeled values and experimental results: the sum of squared errors (SSE) is calculated individually for each model and each experimental data set; the sum of all errors ( $\Sigma S S E)$ according to Eq. (7) for the different experimental data enables a comparison of the different models

\begin{tabular}{|c|c|c|c|c|c|c|}
\hline \multirow{2}{*}{$\begin{array}{l}\text { experimental data sets and } \\
\text { content of comparison }\end{array}$} & \multicolumn{6}{|c|}{ sum of squared errors $(S S E)$} \\
\hline & M1 & $\mathrm{M} 2$ & M3 & M4 & M5 & M6 \\
\hline Fischer et al. [12] & 5.57 & 0.99 & 3.31 & 2.07 & 6.68 & 86.15 \\
\hline Kühn et al. [15] & 0.13 & 0.16 & 0.13 & 0.07 & 0.19 & 15.59 \\
\hline Zhang et al. [16] (large specimens) & 0.06 & 0.06 & 0.09 & 0.07 & 0.16 & 4.39 \\
\hline Zhang et al. [16] (small specimens) & 0.04 & 0.03 & 0.11 & 0.11 & 0.24 & 10.19 \\
\hline$\Sigma S S E$ & 5.8 & 1.3 & 3.6 & 2.3 & 7.3 & 116.3 \\
\hline number of fitting parameters & 2 & 4 & 2 & 3 & 1 & 0 \\
\hline prediction without high-dynamic test & - & - & - & - & yes & yes \\
\hline
\end{tabular}

Note: Fitted models: M1-Tang et al. [26], M2-Gebbeken and Greulich [27], M3-Brara and Klepaczko [28], M4-Li et al. [29], M5- Fischer et al. [12], M6Model Code.

materials, as shown in Fig. 1. Nevertheless, engineering design requires models for the prediction of the ultimate stresses without preceding experiments.

\subsection{Prediction of the ultimate stress in uniaxial dynamic tests}

Engineering design requires models for the prediction of the ultimate stress without preceding experiments. Notably, the word "prediction" originates from the Latin verb "praedicere", meaning "to say in advance", i.e., to forecast, see, e.g., Ref. [31]. However, the European standard for concrete constructions [32] does not contain a model describing the strain-rate effect of the ultimate stress. The fib Model Code [33], which is a prestandardized collection of topics relevant to concrete, 
includes a model for the strain-rate effect. The ultimate stress reached in case of dynamic loading is estimated by a piece-wise power-law function as

$$
\begin{aligned}
& D I F=\left[\frac{\dot{\varepsilon}}{-30 \cdot 10^{-6} \mathrm{~s}^{-1}}\right]^{1.026 /\left(5+9 \frac{f_{\mathrm{sa}}}{10 \mathrm{MPa}}\right)}, \\
& \text { for } \dot{\varepsilon} \leqslant 30 \mathrm{~s}^{-1}, \\
& D I F=10^{\left(6.156 /\left(5+9 \frac{f_{\mathrm{sta}}}{10 \mathrm{MPa}}\right)+2\right)}\left[\frac{\dot{\varepsilon}}{-30 \cdot 10^{-6} \mathrm{~s}^{-1}}\right]^{1 / 3}, \\
& \text { for } \dot{\varepsilon}>30 \mathrm{~s}^{-1} .
\end{aligned}
$$

Equation (8) combines relations from the fib Model Code for practical use. As the quasi-static strength of the material is the only parameter appearing in Eq. (8), a model prediction without previous tests is possible. The model is applied to the experimental test series on cement paste specimens [12], concrete specimens [15], and two different sizes of mortar specimens [16], see the black lines in Figs. 2(a)-2(d).

A comparison of the $f i b$-model prediction (black line) with the experimental values (markers) in Figs. 2(a)-2(d) shows that the prediction overestimates the ultimate stress for the cement paste and for mortar, but underestimates it for concrete. The deviation of the fib-model from the experimental results is calculated with the SSE from

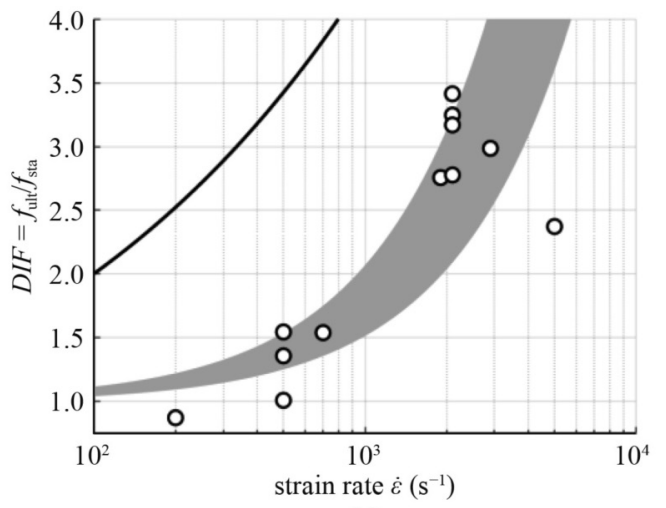

(a)

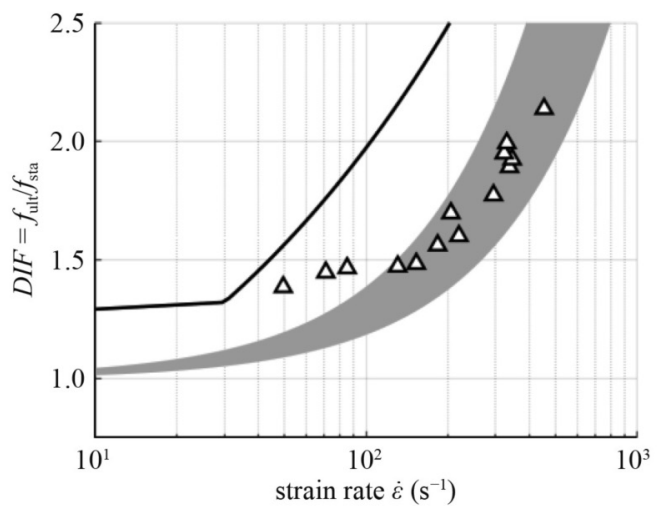

(c)
Eq. (7) and listed in Table 3. Comparing the SSE values obtained from the $f i b$-model with the ones from various models from Subsection 2.3 shows that the SSE values for the $f i b$-model prediction are a multiple of the $S S E$ values obtained from the fitted models.

As the $f i b$-model predictions differ much from the results from the experimental testing campaigns, the predictive capability of the previously discussed models will be investigated next. The fitting parameters of Tang et al. [26] and $\mathrm{Li}$ et al. [29] are not linked to any physical parameters. They vary a lot for the four different experimental data sets, see Table 2 . These facts and lack of values for further predictions render these two models inadequate for predictions. Gebbeken and Greulich [27] have used four fitting parameters. Three of them can be either physically or mathematically interpreted. However, the values of the fitting parameters, summarized in Table 2, do not allow identification of parameters for predictions.

Brara and Klepaczko [28] have introduced two parameters that enable a physical interpretation. The parameter $t_{\mathrm{C}_{0}}$ represents the longest duration of time until the quasi-static strength is reached in dynamic testing. Based on the identified best fitting durations for the considered experiments in Table 2 , it seems that $t_{\mathrm{C}_{0}}$ is

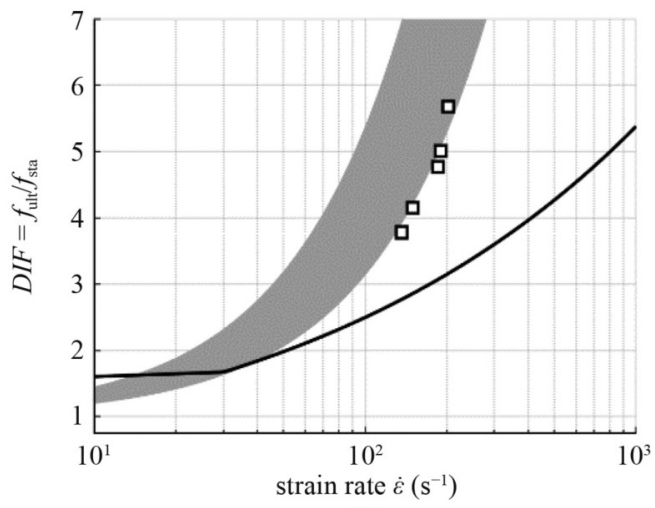

(b)

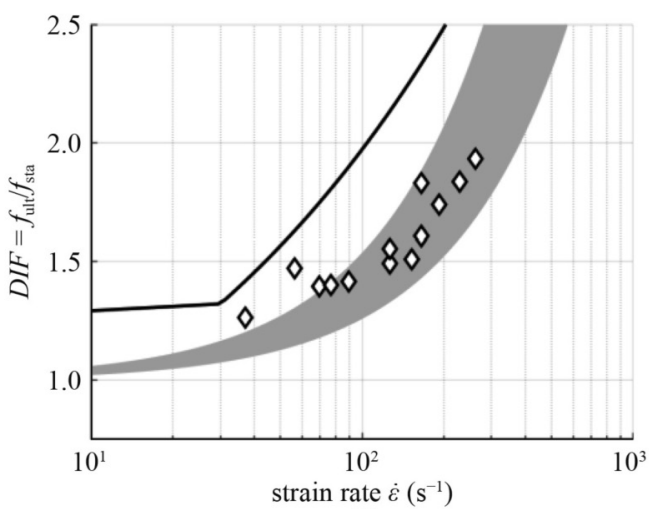

(d)

Fig. 2 Dynamic increase factor of the ultimate stress depending on the strain rate: the black curve shows the fib Model Code prediction, the gray-shaded area illustrates the model prediction according to Fischer et al. [12], and the markers represent the experimental results of (a) Fischer et al. [12], (b) Kühn et al. [15], (c) Zhang et al. [16], for small specimens, (d) Zhang et al. [16], for large specimens. 
shortest for the smallest samples made of cement paste and increases with additional aggregates and with the specimen size. The other parameter, $\xi$, is proportional to the activation energy. Assuming that it is a material parameter, the largest activation energy is required for mortar and the smallest for concrete (see Table 2). As the activation energy was neither determined individually nor in advance of the different experiments, and as the identification of $t_{\mathrm{C}_{0}}$ required a dynamic test, it is impossible to make predictions based on the data provided in the literature.

Fischer et al. [12] have introduced the crack propagation length that leads to separation of the specimen as a fitting parameter, i.e., $F_{\mathrm{h}} h$ in Eq. (6). As for the uniaxial compression test with cracks propagating in the loading direction, Fischer et al. [12] recommend a lower bound for the crack propagation length, equal to one half of the specimen height, and an upper bound, equal to the height of the specimen. Evaluating the engineering mechanics model, given in Eq. (6), for $F_{\mathrm{h}}=0.5$ and $F_{\mathrm{h}}=1.0$, provides a range of the ultimate stress in the considered dynamic experiments. This renders the multi-scale approach of Fischer et al. [12] capable of predicting the results of high-dynamic tests without preceding experiments. Hence, the model of Fischer et al. [12] has a predictive capacity similar to the one of the fib-model. The prediction also considers the experimental dispersion, see the gray shaded area in Figs. 2(a)-2(d).

\subsection{Conclusions}

The following conclusions can be drawn from modeling of the strain-rate effect of the ultimate stress in dynamic testing of cementitious specimens.

1) Lack of information on quantification of the strainrate effect in the current European standard for concrete [32] underlines the need for more research, notwithstanding the fact that, since 1993, the pre-standard Model Code contains a formula for the DIF [33].

2) The expression for the rate-dependent ultimate stress according to the fib Model Code [33] can be applied to any cementitious material with a known quasi-static strength. However, the differences between the predicted $D I F$-values and the experimental results are quite large, suggesting consideration of other models.

3) Fitting of various models has shown that the hyperbolic function recommended by Gebbeken and Greulich [27] can be adapted best to the considered experimental data sets. In this context, it is worth mentioning that the model has the highest number of fitting parameters. The fitted engineering mechanics model by Fischer et al. [12], containing only one fitting parameter, yields the largest errors for the $D I F$-values.

4) Concerning the prediction of the ultimate stress of the dynamic compression test before running dynamic experiments, only the engineering mechanics model of Fischer et al. [12] was able to predict a range of ultimate stress values for the experimental results, based on known material properties and sizes of specimens. This was possible because the multi-scale approach reinforced the comprehension of the physical mechanisms. Fischer et al. [12] could link the increase of the ultimate stress in dynamic testing to a structural effect as described in Section 2.2. The other models from the literature did not provide sufficient information about the fitting parameters to enable independent predictions.

5) The multi-scale approach of Fischer et al. [12] has identified a structural effect that leads to ultimate stresses in dynamic testing that are larger than those in static testing. This agrees with results from other recent research, see Ref. [23]. In future research of the ultimate stress in dynamic testing, it will be necessary to extend the investigations from the material level to the structural level.

\section{Multi-scale thermoelastic analysis of concrete pavements}

\subsection{Temperature field of transient heat conduction}

Concrete pavements are subjected to daily cycles of temperature, i.e., to variable temperature fields. Thermal eigenstrains, associated with temperature changes, are either free, constrained, or prevented to develop, depending on the mechanical constraints. Constrained or prevented thermal eigenstrains lead to thermal stresses that may result in cracking of concrete pavements, degrading their long-term performance.

Quantification of thermal stresses starts with determination of the temperature fields of concrete pavements. For simplicity, it is assumed that, initially, the pavement plate is in an isothermal state, with the reference temperature denoted as $T_{\text {ref }}$. The structure is subjected to thermal loading. It results from solar heating at its top surface, whereas the temperature at the bottom surface of the plate is considered to remain constant at $T_{\text {ref }}$, see Fig. 3. The four lateral surfaces of the plate are assumed to be thermally insulated, see Fig. 3. This leads to one-dimensional heat conduction along the thickness of the pavement plate, i.e., along the $z$-direction. The differential equation concerned can be written as

$$
\frac{\partial T}{\partial t}-a \frac{\partial^{2} T}{\partial z^{2}}=0,
$$

with $a$ standing for the thermal diffusivity of concrete. Evolution of the temperature change at the top surface of the plate is assumed to follow an S-shape function, given as [29] 


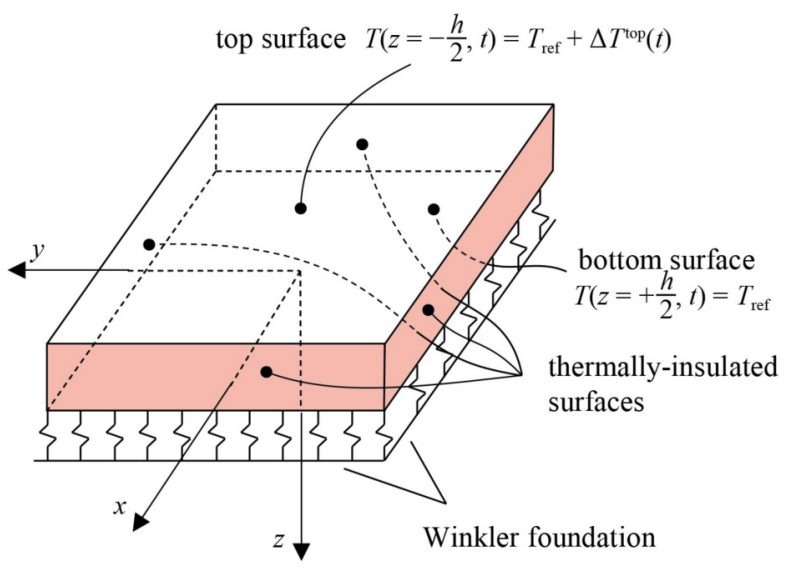

Fig. 3 Pavement plate resting on an elastic Winkler foundation, loaded by a temperature change.

$$
\Delta T^{\mathrm{top}}(t)=\Delta T_{\text {fin }}^{\mathrm{top}} \cdot \frac{1}{2}\left[1-\cos \left(\frac{t \pi}{12 \mathrm{~h}}\right)\right],
$$

with $\Delta T_{\text {fin }}^{\text {top }}$ standing for the maximum increase of the temperature, reached twelve hours after sunrise.

Considering the linearity of Eq. (9), the continuous temperature increase at the top surface of the plate in Fig. 3 is discretized in a step-wise manner, characterized by a temperature increment $\Delta T_{i}^{\text {top }}$ at time step $t_{i}$. The temperature history is subdivided into $S_{i}$ steps such that the total temperature change along the thickness of the plate can be analytically computed as [29]

$$
\begin{aligned}
\Delta T(z, t)= & \sum_{i=1}^{S_{i}} \Delta T_{i}^{\mathrm{top}}\left(\frac{1}{2}-\frac{z}{h}\right) \\
& -\sum_{n}^{\infty} \frac{\Delta T_{i}^{\mathrm{top}}(-1)^{n}}{n \pi} \sin \left(2 n \pi \frac{z}{h}\right) \\
& \exp \left[-(2 n \pi)^{2} \frac{a<t-t_{i}>}{h^{2}}\right] \\
& +\sum_{n}^{\infty} \frac{2 \Delta T_{i}^{\mathrm{top}}(-1)^{n}}{(2 n-1) \pi} \cos \left[(2 n-1) \pi \frac{z}{h}\right] \\
& \exp \left[-(2 n-1)^{2} \pi^{2} \frac{a<t-t_{i}>}{h^{2}}\right],
\end{aligned}
$$

with $<\cdot>$ standing for the Macaulay operator.

The temperature field resulting from the transient heat conduction process is distributed nonlinearly over the thickness, i.e., in the $z$-direction, of the pavement. However, state-of-the-art guidelines, see, e.g., Ref. [34], for calculation of thermal stresses of pavements have been established mainly on the basis of a linearly distributed temperature change over the thickness of the plate. Furthermore, experimental studies have shown that thermally-induced degradation of cementitious materials, resulting in the decrease of the elastic modulus and the compressive strength, originates from microstructural cracking [35-38]. This has motivated the following analysis of the thermal response of concrete pavements across several scales of observation.

3.2 Multi-scale analysis of the thermally-loaded concrete pavement

Multi-scale analysis of the stresses of the thermallyloaded concrete pavement is performed. Thermal eigenstrains, associated with temperature changes, are constrained or prevented at three different scales of observation of the concrete pavement, i.e., constraints at the macrostructural scale of the pavement, at its crosssectional scale, and at the microstructural scale of concrete.

The solution starts with quantifying the thermal stresses at the macrostructural scale and at the cross-sectional scale of the pavement by recalling Kirchhoff's normal hypothesis. It states that, for thin plates, their generators remain straight during deformation. Consequently, the total strains are linearly distributed over the thickness:

$$
\varepsilon_{x x}=\frac{\partial u_{0}}{\partial x}+\left(-\frac{\partial^{2} w_{0}}{\partial x^{2}}\right) z=\varepsilon_{x, 0}+\kappa_{x, 0} z,
$$

with $u_{0}$ and $w_{0}$ standing for the displacement components in the $x$-and the $y$-direction, in the midplane of the plate. This has motivated the decomposition of the nonlinear thermal eigenstrains, associated with the transient heat conduction, into a linear and a nonlinear part. The former is related to an eigenstretch $\varepsilon_{0}^{\mathrm{e}}$ of the plate and an eigencurvature $\kappa_{0}^{\mathrm{e}}$ of its midplane, defined as

$$
\varepsilon_{0}^{\mathrm{e}}=\frac{1}{h} \int_{z} \alpha \Delta T \mathrm{~d} z
$$

and

$$
\kappa_{0}^{\mathrm{e}}=\frac{12}{h^{3}} \int_{z} \alpha \Delta T z \mathrm{~d} z,
$$

respectively, with $\alpha$ standing for the thermal expansion coefficient of concrete. The residual nonlinear part of the thermal eigenstrains represents an eigendistortion of the plate generators, given as

$$
\varepsilon_{\mathrm{dis}}^{\mathrm{e}}=\alpha \Delta T-\varepsilon_{0}^{\mathrm{e}}-\kappa_{0}^{\mathrm{e}} z .
$$

Based on the assumption of generators of the plate remaining straight during deformation, i.e., obeying Kirchhoff's normal hypothesis, there should be no eigendistortion at the scale of the cross-section of the plate. This results in an elastic strain equal to the opposite value of the eigendistortion defined in Eq. (15). The elastic strain leads to self-equilibrated thermal stress due to the constraints at the cross-sectional scale of the plate.

The magnitude of the thermal stresses related to the eigenstretch and the eigencurvature depends on the constraints at the macrostructural scale of the pavement plate. The eigenstretch, as the mean value of the 
eigenstrain, see Eq. (13), stands for the eigentensile/compressive strain of the plate. Considering the joints between neighboring plates of the pavement, this eigenstretch is free to develop. The eigencurvature is the first-order moment of the eigenstrain, see Eq. (14). However, this eigencurvature is restrained by the foundation of the plate. This leads to thermal stresses as a result of constraints at the macrostructural scale of the plate.

The mismatch of the thermoelastic properties of the concrete constituents and their mutual interaction results in a microstructural stress fluctuation in the concrete pavement. Concrete is considered as a composite with coarse aggregates embedded in the matrix of mortar. The latter consists of fine aggregates surrounded by the cement paste matrix. The microstructure of concrete is loaded by a macroscopic strain $E_{\text {hom }}$ and a temperature change $\Delta T$. The resulting average strains of the matrix phase and the inclusion phase can be quantified, following the concentration-influence relation [39]

$$
\varepsilon_{p}=\mathbb{A}_{p}: E_{\mathrm{hom}}+\sum_{q=m, i} \mathbb{D}_{p q}: \varepsilon_{q}^{\mathrm{e}}, p \in[m ; i],
$$

with $\mathbb{A}_{p}$ and $\mathbb{D}_{p q}$ denoting the strain concentration tensor and the eigenstrain influence tensor, respectively. For $q=p$, the latter expresses the influence of the eigenstrain of phase $p$ on its own total microstrain, given as

$$
\mathbb{D}_{p p}=\left[\mathbb{I}-f_{p} \mathbb{A}_{p}\right]:\left[\mathbb{I}+\mathbb{S}: \mathbb{C}_{\mathrm{m}}^{-1}:\left(\mathbb{C}_{p}-\mathbb{C}_{\mathrm{m}}\right)\right]^{-1}:\left(\mathbb{S}-\mathbb{C}_{\mathrm{m}}\right)^{-1}: \mathbb{C}_{p},
$$

and for $q \neq p$, it expresses the influence of the eigenstrain of phase $q$ on the total microstrain of phase $p$, given as

$$
\mathbb{D}_{p q}=-\mathbb{A}_{p}: f_{p}\left[\mathbb{I}+\mathbb{S}: \mathbb{C}_{\mathrm{m}}^{-1}:\left(\mathbb{C}_{p}-\mathbb{C}_{\mathrm{m}}\right)\right]^{-1}:\left(\mathbb{S}-\mathbb{C}_{\mathrm{m}}\right)^{-1}: \mathbb{C}_{p},
$$

with $f_{p}$ and $\mathbb{C}_{p}$ standing for the volume fraction and stiffness tensor of phase $p$, respectively. II and $\mathbb{S}$ represent the symmetric fourth-order unity tensor and the Eshelby tensor of a spherical inclusion, embedded in an infinite matrix of stiffness $\mathbb{C}_{\mathrm{m}}$. By recalling the standard elasticity law, the microscopic average stresses of the matrix and inclusion phases are finally quantified.

\subsection{Exemplary study}

The described mode of multi-scale thermoelastic analysis of a pavement plate is exemplarily applied to compute the thermal stresses of a concrete pavement with different magnitudes of internal $R H$. This is done in order to answer the question of the added value of multi-scale structural analysis. Figure 4 shows that the thermal expansion coefficient of the cement paste, as the main constituent of concrete, varies significantly with the internal $R H[40,41]$. Therefore, the thermal expansion coefficient of concrete also varies with the internal $R H$ [41]. However, this coefficient is generally taken as a constant value around $10 \times 10^{-6}{ }^{\circ} \mathrm{C}^{-1}$, see Ref. [42] for example.

The dimensions of the pavement plate read as $l_{x} \times l_{y} \times h=5.00 \mathrm{~m} \times 3.75 \mathrm{~m} \times 0.25 \mathrm{~m}$. The mass density and the thermal diffusivity of concrete are taken as $2400 \mathrm{~kg} / \mathrm{m}^{3}$ and $4.73 \times 10^{-7} \mathrm{~m}^{2} / \mathrm{s}$, respectively. By assuming a maximum temperature increase of $\Delta T_{\text {fin }}^{\text {top }}=$ $45^{\circ} \mathrm{C}$, the temperature change along the height of the pavement can be computed by means of Eq. (12), see Fig. 5(a).

Quantification of the resulting thermal eigenstrains is related to the magnitude of the thermal expansion coefficient of concrete. The latter changes with the internal $R H$, which is taken herein as $R H=50 \%$, $R H=65 \%$, and $R H=100 \%$. Identification of the thermoelastic parameters of concrete follows from bottom-up homogenization from the level of the cement paste, via the level of mortar, up to the level of concrete, see Ref. [47] for details and Table 4 for the input and output parameters. The latter are highlighted in bold face.

The thermal eigenstrains across the thickness of the pavement plate are computed by multiplying the temperature change with the thermal expansion coefficient of concrete. They are distributed in a fashion similar to the one of the temperature changes, compare Fig. 5(a) with Figs. 5(b)-5(d), because the thermal expansion coefficient of concrete is considered to be independent of the position inside the plate. The total thermal eigenstrains are decomposed into three components, i.e., into those related to the eigenstretch, the eigencurvature, and the eigendistortion following Eqs. (13)-(15), see Figs. 5(b)-5(d). Superposition of the first two parts represents the linear part of the total thermal eigenstrains, whereas the eigendistortion

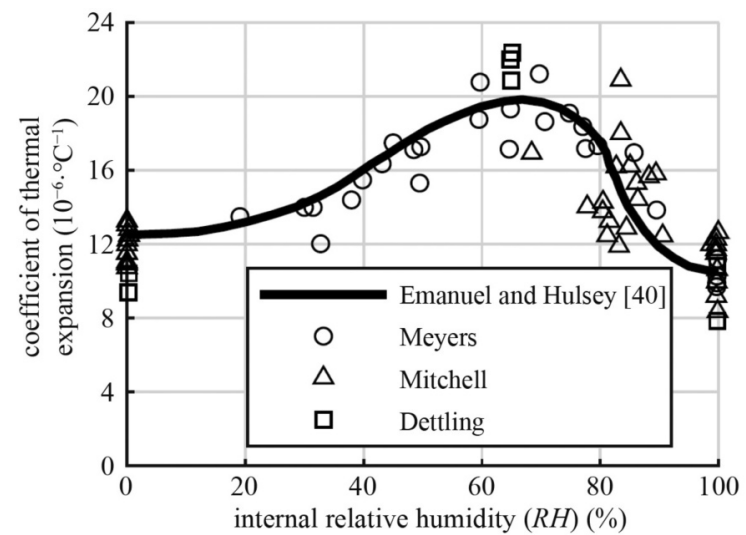

Fig. 4 Thermal expansion coefficient of the cement paste, depending on the internal $R H$, see Ref. [43]; the curve refers to a fitting function used by Emanuel and Hulsey [40] and the markers represent the experimental results of Meyers [44], Mitchell [45], and Dettling [46]. 
represents the nonlinear part. Notably, the effect of creep, shrinkage, and friction is not included herein.

For quantification of the thermal stresses related to the constraints at the macrostructural scale of the pavement plate, an elastic Winkler foundation of the plate is considered. Its modulus of reaction is assumed as $100 \mathrm{MPa} / \mathrm{m}$. The structural response of the plate is studied, following the semi-analytical procedure established by Höller et al. [48], based on the principle of

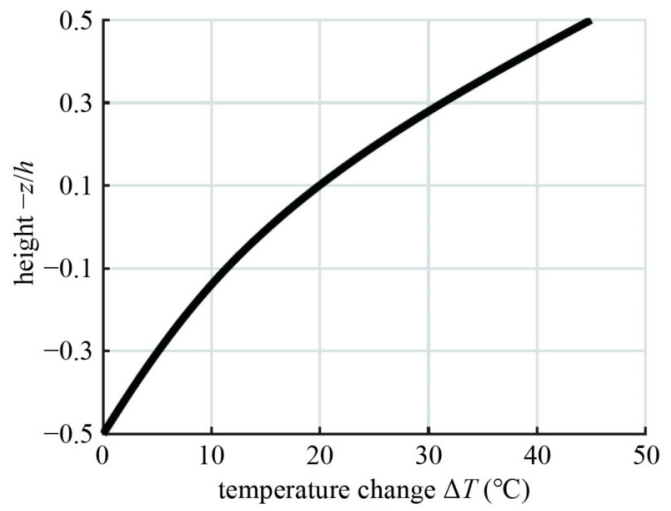

(a)

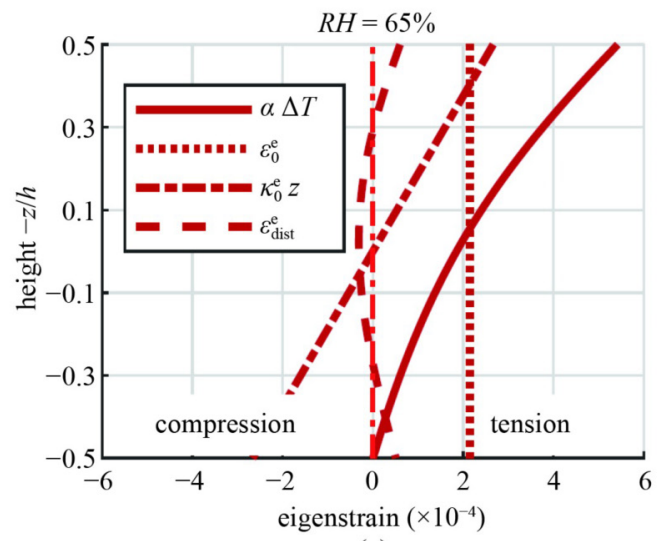

(c) the virtual power, see Fig. 6(a). The quantified stresses are distributed linearly along the height of the beam. They are quite similar for the three magnitudes of the internal $R H$. They represent the structural response to the thermal loading, considering the constraints at the macrostructural scale of the pavement. Notably, quantification of the thermal stresses induced by the linear part of the eigenstrains, i.e., from the eigenstretch and the eigencurvature, is consistent with the conventional

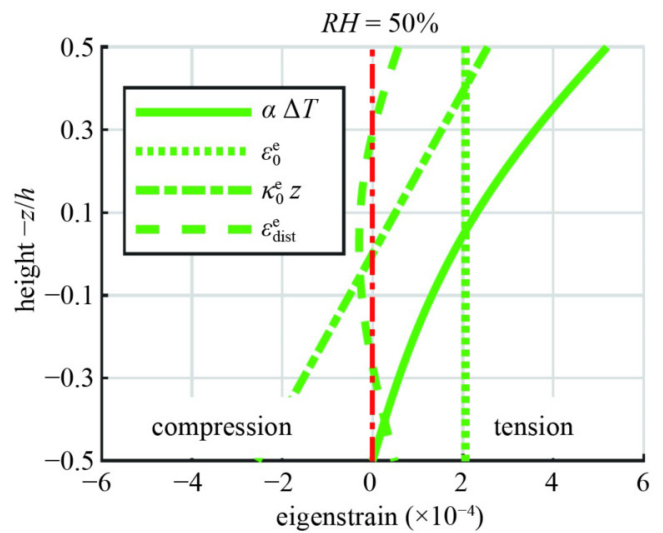

(b)

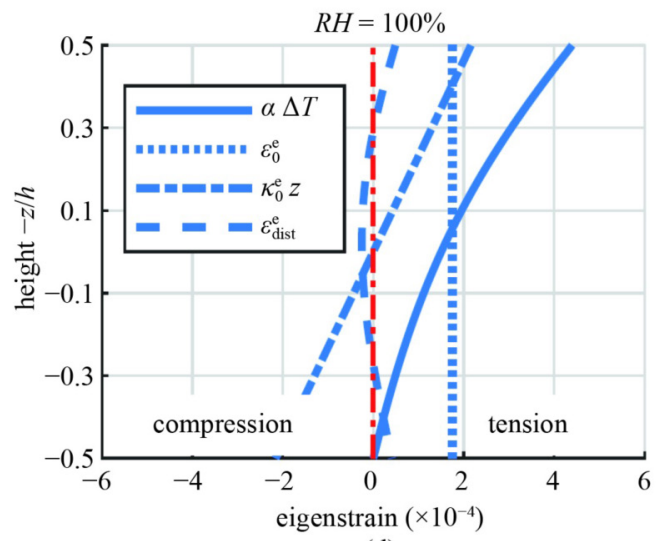

(d)

Fig. 5 (a) Distribution of the temperature change over the thickness of the pavement plate and decomposition of the resulting thermal eigenstrains into those related to the eigenstretch, the eigencurvature, and the eigendistortion for a pavement, with internal $R H$ amounting to (b) $50 \%$, (c) $65 \%$, and (d) $100 \%$, respectively.

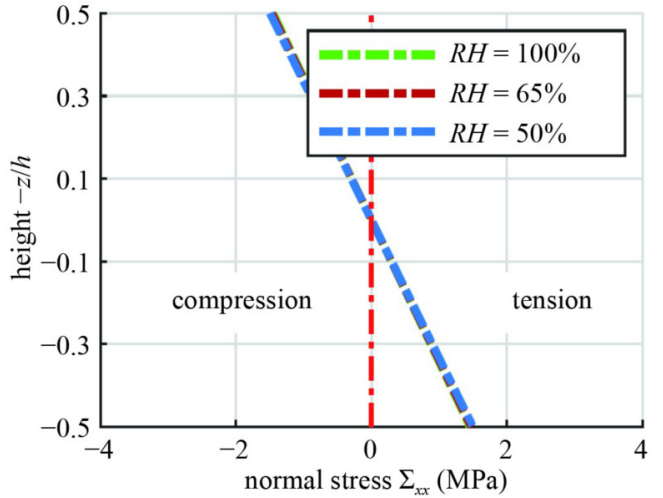

(a)

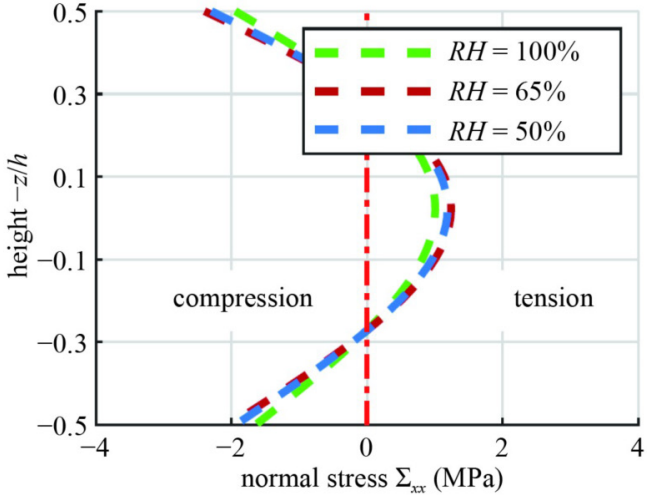

(b)

Fig. 6 Macroscopic thermal stresses resulting from (a) the constrained eigencurvature and (b) the prevented eigendistortion. 
solution for the thermal stresses, considering a temperature field, linearly distributed over the thickness of the plate.

The nonlinear part of the eigenstrains is prevented by the constraints at the scale of the cross-section of the plate, which results in thermal stresses, see Fig. 6(b). Compressive stresses are observed at the top and the bottom part of the pavement, whereas the middle part is subjected to tensile stresses. It is worth mentioning that these stresses are self-equilibrating, i.e., their mean value and first-order of moment along the thickness of the plate are equal to zero.

Superposition of the thermal stresses resulting from the constrained eigencurvature and from the prevented eigendistortion leads to the total macroscopic thermal stresses, see Fig. 7. The largest compressive stresses are observed at the top surface of the pavement, reaching the magnitudes of $3.79,3.87$, and $3.40 \mathrm{MPa}$ for $R H=50 \%$, $65 \%$, and $100 \%$, respectively, whereas the largest tensile stresses are observed in the middle part of the plate, reading as $1.26,1.30$, and $1.10 \mathrm{MPa}$ for the three relative humidities. This underlines that thermal stresses related to daily temperature cycles threaten the durability of the pavement plate, especially in its invisible middle part.

The established multi-scale solution contains quantification of the microscopic stresses of the concrete constituents in two steps, following Eq. (16). Starting from the level of concrete, the stress states of the coarse aggregate inclusions and of the mortar matrix are computed. The latter serve as input, at the level of mortar, for the following subsequent quantification of the stress states of the fine aggregate inclusions and the cement paste matrix, see Ref. [48] for details. The microstresses of the concrete constituents generally fluctuate around the macrostresses, see Fig. 8. This fluctuation originates from the mismatch of the thermoelastic properties of the constituents of the statically indeterminate microstructure of concrete, in consequence of bond between the concrete constituents. Inside the matrix-inclusion composite of

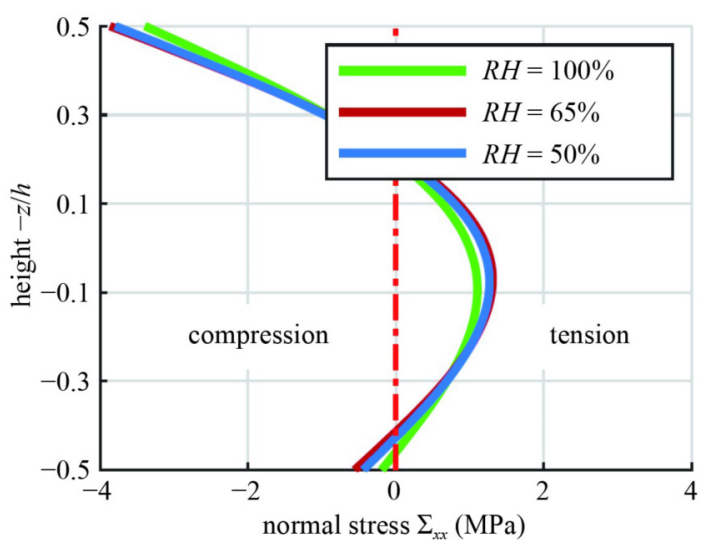

Fig. 7 Total thermal stresses of the pavement plate, loaded by a daily temperature evolution. concrete/mortar, the stiffer constituent takes a larger part of the macrostresses than the less stiff constituent. On the other hand, the constituent with a smaller/larger thermal expansion coefficient is subjected to tension/compression in case of heating.

Although the macrostresses of concrete are quite similar for the three magnitudes of $R H$, see Fig. 7, the microstresses of the concrete constituents differ significantly, see Fig. 8. At the scale of concrete, the fluctuation of the microstresses of mortar and of the coarse aggregates around the macrostresses of concrete is mainly attributed to the mismatch of their coefficients of thermal expansion. The thermal expansion coefficients of mortar with $R H=50 \%, 65 \%$, and $100 \%$ are larger than those of the coarse aggregates, see Table 4, resulting in a smaller magnitude of the microstresses of the mortar as compared to those of the coarse aggregates. Notably, for $R H=50 \%$ and $65 \%$, the coarse aggregates are subjected to microscopic tensile stresses almost across the whole thickness of the pavement. These tensile stresses are transferred to the interfacial transition zones (ITZs), covering the surfaces of the aggregates. Firm bond between the aggregates and the surrounding ITZ is considered. Thus, both the displacements and the traction vectors are continuous across the interface. Together with the known thermoelastic behavior of the ITZ, this provides access to the microstresses inside the ITZ, which vary along the surface of the aggregates. Stresses in the ITZ can be even larger than the microstress of the surrounding matrix phase, see Refs. [41,47,49,50] for details. Furthermore, ITZs are generally considered to be the "weakest links" inside the microstructure of concrete, because of their larger porosity. This underlines the risk of tensile cracking in these weak interfaces $[47,49,50]$. At the scale of observation of the mortar, the thermal expansion coefficient of the fully saturated cement paste, i.e., $R H=100 \%$, is smaller than that of the fine aggregates. In this scenario, the increase of temperature gives rise to larger expansive eigenstrains of the fine aggregates compared to those of the cement paste. The compatibility of the total microscopic strain fields results in an additional contribution to the compressive stresses of the fine aggregates. Whereas, this compatibility results in a counteraction to the compressive stresses of the cement paste [51]. Therefore, the total compressive stresses of the fine aggregates are larger than those of the cement paste. However, in case of partially saturated scenarios, the total compressive stresses of the fine aggregates are found be smaller than those of the cement paste. This is attribute to the larger thermal expansion coefficient of the cement paste compared to that of the fine aggregates in this case.

\subsection{Conclusions}

A concept for multi-scale analysis of thermally-loaded concrete pavements was presented. It is based on 


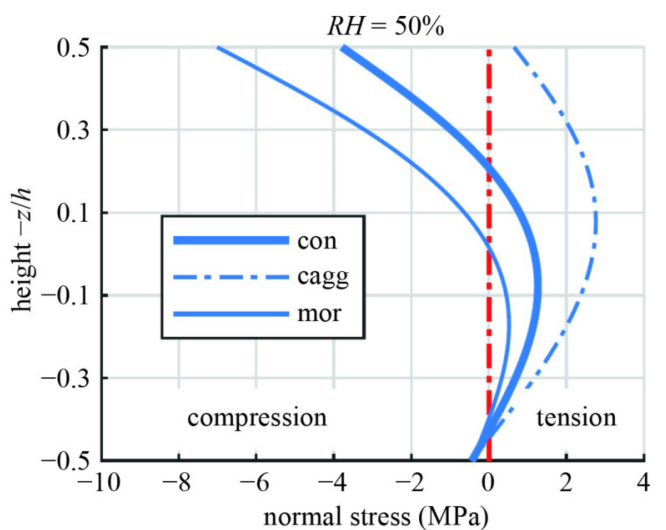

(a)

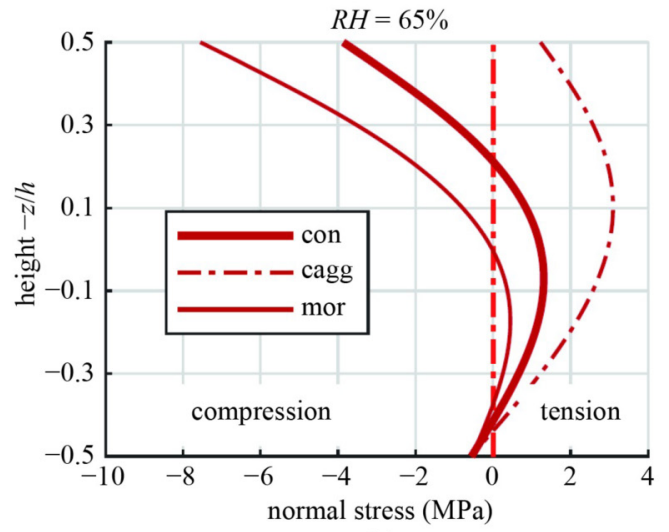

(c)

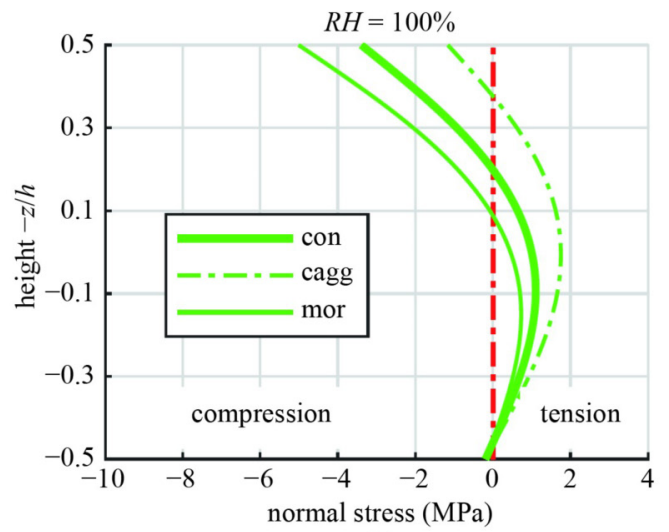

(e)

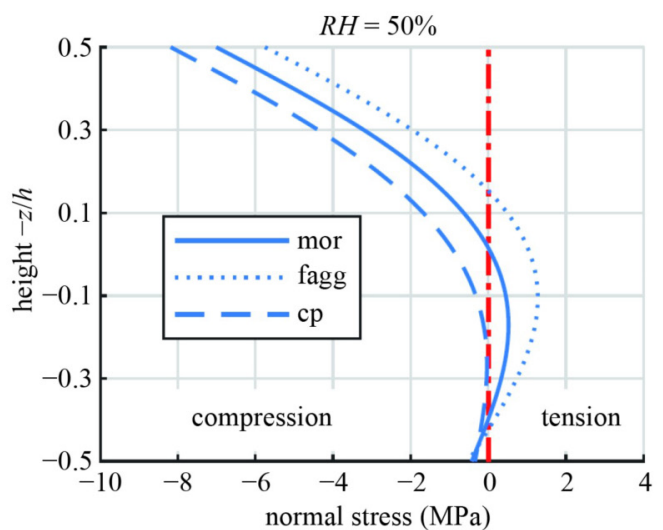

(b)

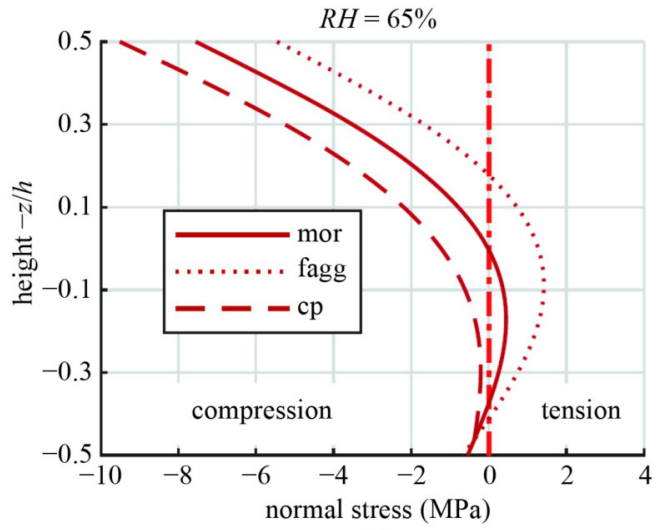

(d)

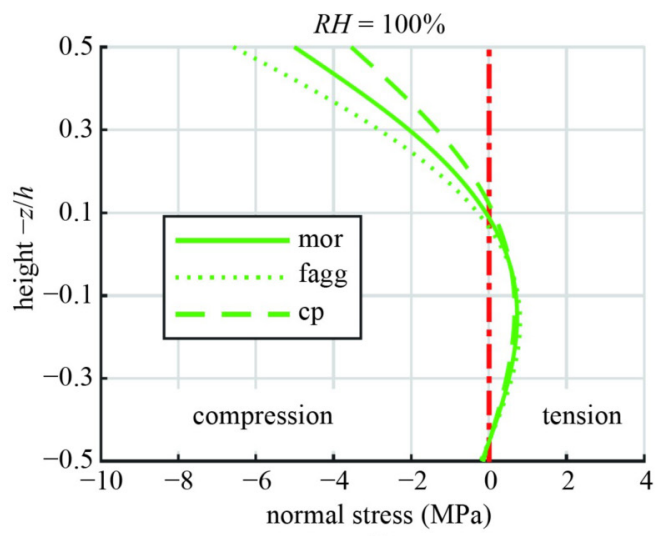

(f)

Fig. 8 Thermally loaded concrete: macroscopic stresses of concrete and microscopic stresses of its constituents $($ con $=$ concrete, cagg $=$ coarse aggregates, $\operatorname{mor}=$ mortar, fagg $=$ fine aggregates, $\mathrm{cp}=$ cement paste), with internal relative humidity amounting to (a) and (b) $50 \%$; (c) and (d) 65\%; as well as (e) and (f) $100 \%$, respectively.

Table 4 Properties of concrete and its constituents: volume fractions, elastic constants, and thermal expansion coefficients; with output highlighted in bold face

\begin{tabular}{|c|c|c|c|c|c|c|}
\hline \multirow[t]{2}{*}{ material } & \multirow[t]{2}{*}{ volume fraction } & \multirow[t]{2}{*}{ bulk modulus (GPa) } & \multirow[t]{2}{*}{ shear modulus (GPa) } & \multicolumn{3}{|c|}{ thermal expansion coefficient $\left(10^{-6}{ }^{\circ} \mathrm{C}^{-1}\right)$} \\
\hline & & & & $R H=50 \%$ & $R H=65 \%$ & $R H=100 \%$ \\
\hline concrete & - & 17.8 & 13.2 & 11.5 & 12.1 & 9.8 \\
\hline mortar & - & 17.4 & 14.0 & 14.2 & 15.1 & 11.1 \\
\hline cement paste & 0.30 & 10.2 & 7.7 & 18.0 & 20.2 & 10.5 \\
\hline fine aggregate & 0.28 & 33.8 & 30.8 & - & 11.5 & - \\
\hline coarse aggregate & 0.42 & 18.5 & 12.2 & - & 8.0 & - \\
\hline
\end{tabular}


Kirchhoff's normal hypothesis of thin plates and on the concentration-influence relations of continuum micromechanics. This concept was thermal stresses of concrete pavement with different magnitudes of internal $R H$. The following conclusions are drawn.

1) Daily cycles of temperature are important loading scenarios to assess the long-term durability of concrete pavements. Tensile cracking may prevail in the inaccessible middle part of the plate. This requires careful inspection, such as one by ultrasonic tomography.

2) The influence of the internal $R H$ on the macrostresses of concrete is insignificant, whereas the microstresses of the concrete constituents vary remarkably with this quantity. Therefore, the magnitude of the internal $R H$ is of vital importance for studying microcracking of concrete, especially inside the ITZs covering the aggregates. The microstresses of these weak interfaces are quantified, using the aggregate-to-ITZ stress transfer relations, derived from the continuity of the displacements and traction vectors across the interfaces.

3) The presented multi-scale analysis of concrete pavements provides additional information, ranging from the microscopic scale of concrete materials up to the macroscopic scale of concrete structures.

\section{Multi-scale analysis of a tunnel ring}

\subsection{Experimental data}

Herein, experimental data are taken from a real-scale test of a segmental tunnel ring. This test is representative of a series of tests carried out at Tongji University. Photos of the test set-ups are shown in Fig. 9. Early tests focused on the bearing capacity of standard single rings [52]. They were followed by tests on strengthened single rings with the help of steel shells [53], filament wound profiles [54], steel-concrete composites [55], and Ultra-High Performance Concrete (UHPC) [56]. In case of insignificant ring-to-ring interaction, it is reasonable to restrict the experimental investigations to tests of single rings [57]. However, for some loading scenarios, such as large axial loading [58], this interaction may become strong. This applies to tunnel linings with misaligned longitudinal joints of neighboring rings [59] and to varying ground pressure in the axial direction [60]. This is the situation investigated in recent real-scale tests of three tunnel rings, considering ring-to-ring interaction [61-63].

In the present paper, a test of a single ring, reported in Ref. [49], is investigated. This selection is motivated by the accessibility of both experimental results and multiscale structural analysis of the tested ring [64]. The ring is an assemblage of six reinforced concrete segments, see Fig. 10(a). The radius of its axis, $R$, is $2.925 \mathrm{~m}$. The width, $H$, is equal to $35 \mathrm{~cm}$. The thickness, $B$, amounts to $1.2 \mathrm{~m}$. The external load was imposed by 24 hydraulic jacks. The latter were subdivided into three groups, producing the loads $P_{1}, P_{2}, P_{3}$, see Fig. 10(b) and also Ref. [52] for the detailed loading scheme. Structural monitoring was concerned with the convergences in the vertical and the horizontal direction as well as with the circumferential displacement jumps across the outer and inner gaps of the six joints, see their diagrams in Ref. [64]. Moreover, the values of the external loading, at which bending-induced cracking of the tunnel segments was observed, were documented. Cracking started when $P_{1}$ reached the value of $0.117 \mathrm{MN}$. At the final load step, i.e., for $P_{1}$ equal to $0.448 \mathrm{MN}$, the maximum crack opening of the segments was in the range of $[0.05 \mathrm{~mm}$, $0.10 \mathrm{~mm}$ ]. Cracking of concrete has rendered modeling of tensile softening of concrete necessary for re-analysis of the tunnel ring. It can be modeled either by a conventional or a multi-scale approach, described in Subsections 4.2 and 4.3, respectively, dealing with conventional and multi-scale structural analysis, presented in Subsection 4.4.

\subsection{Conventional approaches to describe the tensile strength and softening of concrete}

The raw materials of the concrete used for the tunnel segments include cement, water, slag, fly ash, sand, and aggregates. The mix design is contained in Table 5. The concrete grade was C55. The maximum size of the aggregates, $d_{\max }$, amounted to $20 \mathrm{~mm}$. The experimentally

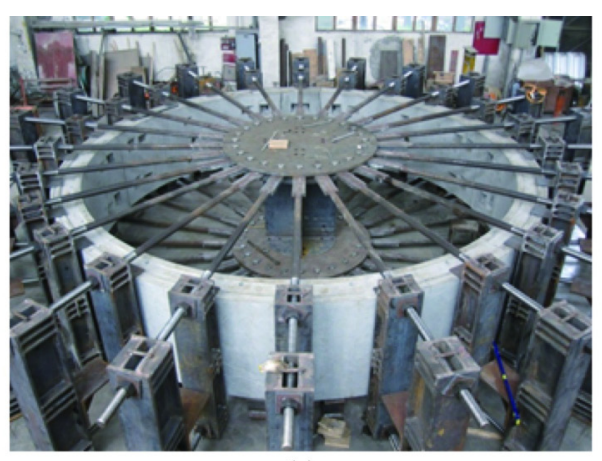

(a)

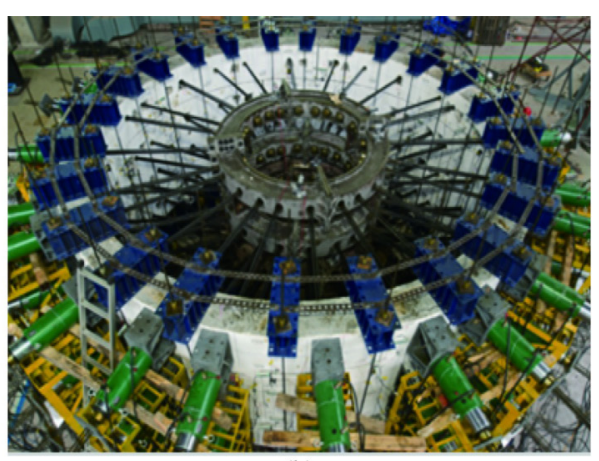

(b)

Fig. 9 Set-ups of real-scale tests of segmental tunnel rings at Tongji University: (a) single ring [52] and (b) three rings allowing consideration of ring-to-ring interaction [61]. 


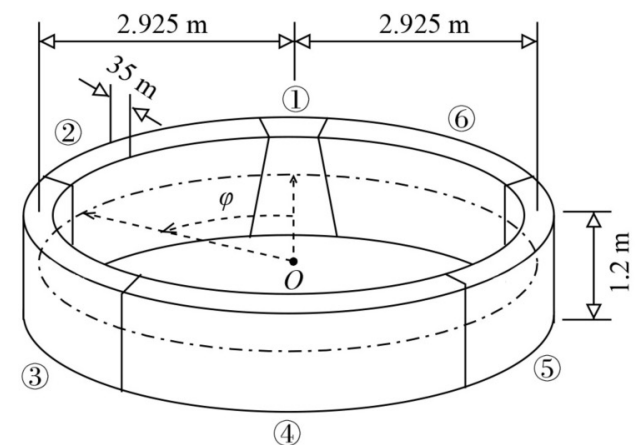

(a)

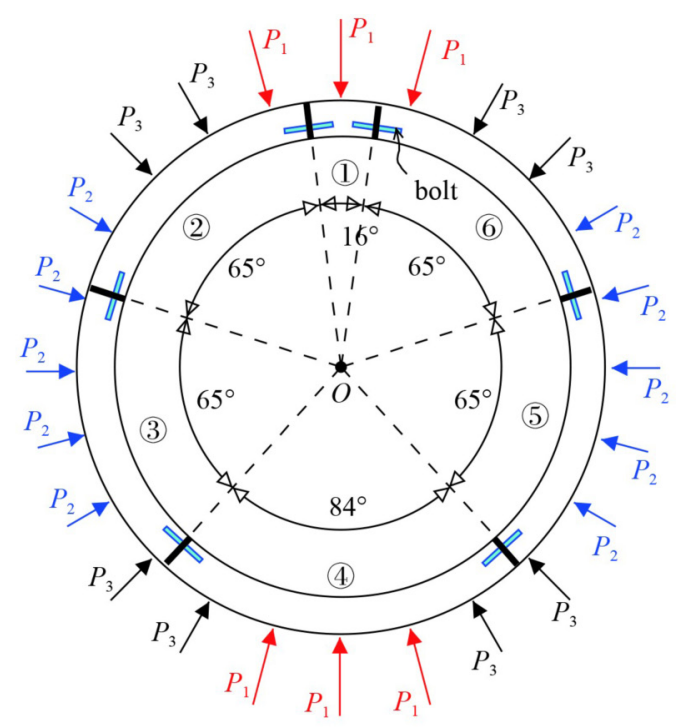

(b)

Fig. 10 Test of a single ring, reported in Ref. [52]: (a) geometric dimensions of the ring [64] and (b) layout of the hydraulic jacks, producing the loads $P_{1}, P_{2}, P_{3}[65]$.

determined compressive strength of the concrete at the age of $28 \mathrm{~d}$ was equal to $58 \mathrm{MPa}$. Three conventional approaches for the determination of the tensile strength and quantification of softening of concrete are considered herein. They refer to 1) the fib Model Code [66], 2) the guidelines for concrete of the Japanese Society of Civil Engineering (JSCE) [67], and 3) the Chinese code for the design of concrete structures [68]. In the present paper, the designations of these approaches are abbreviated as $f i b$ code, JSCE code, and GB50010 code.

According to the $f i b$ code, the tensile strength, $f_{t}$, Young's modulus, $E$, and the fracture energy, $G$, of concrete can be determined from its compressive strength, $f_{\mathrm{c}}$. As for the investigated concrete, the results are given as follows:

$$
\begin{aligned}
& f_{\mathrm{t}}=4.30 \mathrm{MPa}, \\
& E=40.3 \mathrm{GPa}, \\
& G=154 \mathrm{~N} / \mathrm{m} .
\end{aligned}
$$

With these quantities the strains can be related to the stresses of concrete in tension, see the diagram in Fig. 11(a) and details for calculations in Ref. [69].

The JSCE code uses the experimentally determined compressive strength of concrete, $f_{\mathrm{c}}=58 \mathrm{MPa}$, and the maximum size of the aggregates, $d_{\max }=20 \mathrm{~mm}$, as input. The values of $f_{t}, E$, and $G$, are obtained as

$$
\begin{gathered}
f_{\mathrm{t}}=0.23 f_{\mathrm{c}}^{2 / 3}=3.45 \mathrm{MPa}, \\
E=34.60 \mathrm{GPa},
\end{gathered}
$$

$$
G=10\left(d_{\max }\right)^{1 / 3} \cdot\left(f_{\mathrm{c}}\right)^{1 / 3}=105.07 \mathrm{~N} / \mathrm{m} .
$$

Table 5 Mix design of the concrete of the segments $\left(\mathrm{kg} / \mathrm{m}^{3}\right)$

\begin{tabular}{lccccc}
\hline cement & fly ash & slag & water & sand & aggregates \\
\hline 323 & 67 & 57 & 152 & 631 & 1169 \\
\hline
\end{tabular}

The JSCE code suggests a linear curve, describing the relations between the stresses and the strains for uncracked concrete in tension. As for the tension softening of cracked concrete, another bilinear curve is given. It describes the relationship between the stress ratio, $\sigma / f_{\mathrm{t}}$, and the dimensionless crack width, $w \cdot f_{\mathrm{t}} / G$, where $w$ stands for the crack width. It is estimated as [69]

$$
w=3 d_{\max } \cdot\left[\varepsilon-\frac{f_{\mathrm{t}}}{E}\right] .
$$

The bilinear curve is the basis for derivation of the stressstrain relation for cracked concrete. The obtained stressstrain relation, based on the JSCE code, is illustrated in Fig. 11(b).

The GB50010 code provides lookup tables for characteristic values of the tensile strength and of Young's modulus of the C55 concrete:

$$
\begin{gathered}
f_{\mathrm{t}}=2.74 \mathrm{MPa}, \\
E=35.5 \mathrm{GPa} .
\end{gathered}
$$

The formula, relating the strain to the stress, reads as

$$
\sigma=\left(1-d_{\mathrm{t}}\right) \cdot E \cdot \varepsilon,
$$

where $d_{\mathrm{t}}$ denotes a damage parameter, given as 


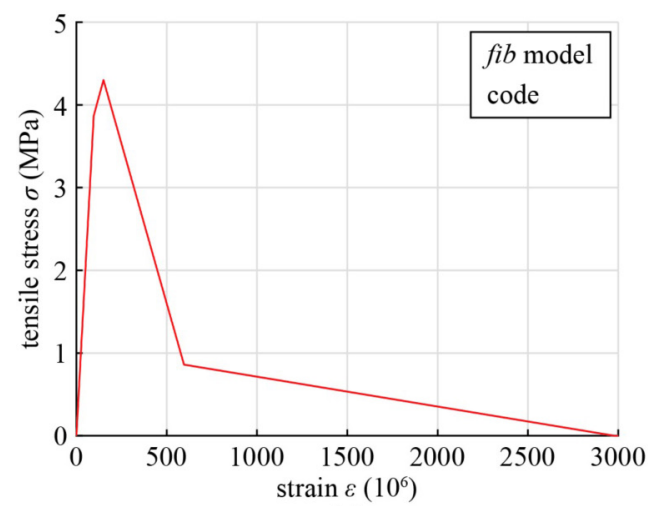

(a)

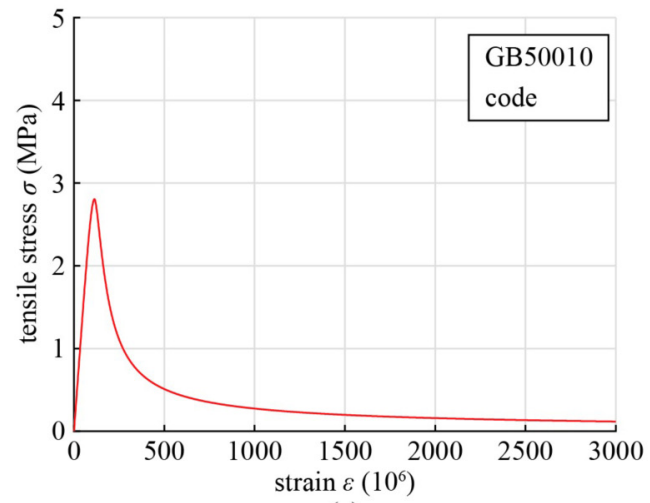

(c)

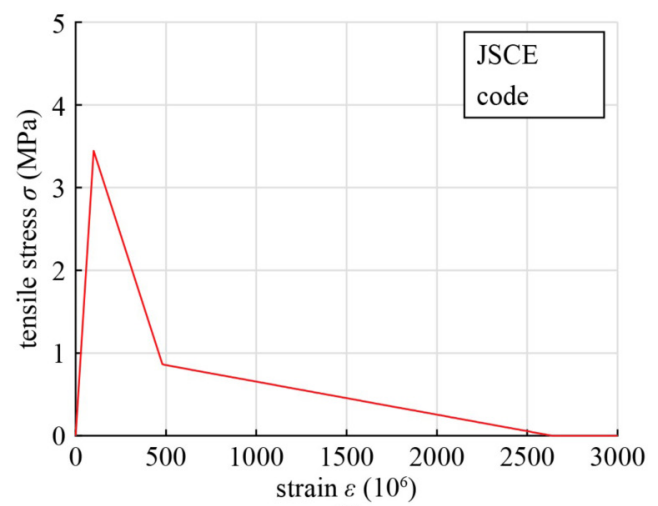

(b)

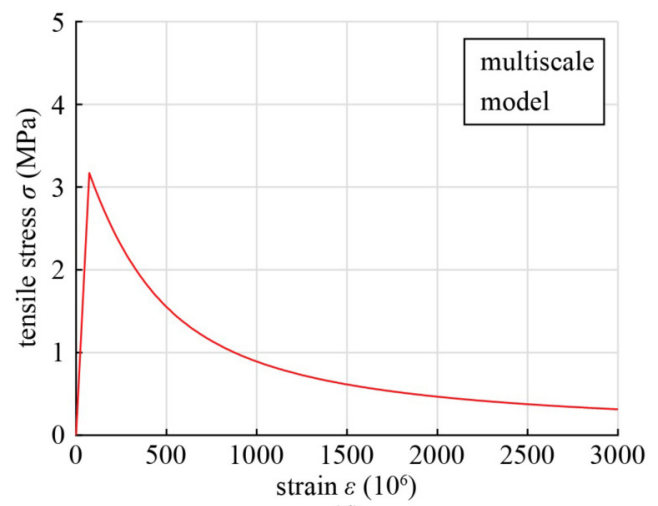

(d)

Fig. 11 Stress-strain relations of the concrete of tunnel segments of the tested ring in Ref. [1], obtained by means of formulae in (a) the fib Model Code [66]; (b) the JSCE Guidelines for Concrete [67]; (c) the GB50010-2010 [68]; (d) by the multi-scale model.

$$
d_{\mathrm{t}}=\left\{\begin{array}{l}
1-0.69\left[1.2-0.2 x^{5}\right], x \leqslant 1, \\
1-\frac{0.69}{2.48(x-1)^{1.7}+x}, x>1,
\end{array}\right.
$$

with $x=\varepsilon / 0.001137$. The obtained stress-strain relation is illustrated in Fig. 11(c).

4.3 Multi-scale approach to describe tensile softening of concrete

Input for this multi-scale approach is the mix proportion and the maturity of the concrete, see details in Refs. [64,69]. As for the homogenization of Young's modulus and of the compressive strength, the multi-scale model by Königsberger et al. [70] was employed. It was developed in the framework of continuum micromechanics $[5,71]$. The homogenization results are obtained as $[64,69]$

$$
\begin{aligned}
& E=43.6 \mathrm{GPa}, \\
& f_{\mathrm{c}}=62.0 \mathrm{MPa} .
\end{aligned}
$$

It is worth mentioning that the predicted value of the compressive strength is close to that obtained from experiments. This corroborates the usefulness of the employed multi-scale approach. As for homogenization of the tensile strength and description of tensile softening of concrete, the multi-scale model by Hlobil [14] was employed. The obtained results read as [64,69]:

$$
\begin{gathered}
f_{\mathrm{t}}=3.17 \mathrm{MPa}, \\
E_{\mathrm{d}}(\omega)=\frac{1}{1+5.02 \omega} \cdot E, \\
f_{\mathrm{t}, \mathrm{d}}=\sqrt{\frac{0.402}{0.402+0.396 \omega}} \cdot f_{\mathrm{t}} .
\end{gathered}
$$

In Eqs. (15) and (16), $E_{\mathrm{d}}$ and $f_{\mathrm{t}, \mathrm{d}}$ denote the elastic stiffness and the tensile strength of concrete during softening. These quantities are decreasing with increasing crack density $\omega$. The stress-strain relation of concrete in tension is obtained with the help of Eqs. (12) and (14)-(16), see the diagram in Fig. 11(d) and the details for the calculations in Refs. $[64,69]$.

\subsection{Structural analysis}

Transfer relations are the basis for structural analysis of the tunnel ring. They represent analytical solutions of the linear theory of slender circular arches [65,72]. These relations read as 


$$
\left[\begin{array}{c}
u(\varphi) \\
v(\varphi) \\
\theta(\varphi) \\
M(\varphi) \\
N(\varphi) \\
V(\varphi) \\
\cdots \\
1
\end{array}\right]=\left[\begin{array}{cccccccc}
\cos \varphi & \sin \varphi & T_{13}(\varphi) & T_{14}(\varphi) & T_{15}(\varphi) & T_{16}(\varphi) & \cdots & \sum u^{\mathrm{L}}(\varphi) \\
-\sin \varphi & \cos \varphi & T_{23}(\varphi) & T_{24}(\varphi) & T_{25}(\varphi) & T_{26}(\varphi) & \cdots & \sum v^{\mathrm{L}}(\varphi) \\
0 & 0 & 1 & T_{34}(\varphi) & T_{35}(\varphi) & T_{36}(\varphi) & \cdots & \sum \theta^{\mathrm{L}}(\varphi) \\
0 & 0 & 0 & 1 & T_{45}(\varphi) & T_{46}(\varphi) & \cdots & \sum M^{\mathrm{L}}(\varphi) \\
0 & 0 & 0 & 0 & \cos \varphi & -\sin \varphi & \cdots & \sum N^{\mathrm{L}}(\varphi) \\
0 & 0 & 0 & 0 & \sin \varphi & \cos \varphi & \cdots & \sum V^{\mathrm{L}}(\varphi) \\
\cdots & \cdots & \cdots & \cdots & \cdots & \cdots & \cdots & \cdots \\
0 & 0 & 0 & 0 & 0 & 0 & \cdots & 1
\end{array}\right] \cdot\left[\begin{array}{c}
u_{\mathrm{i}}(\varphi) \\
v_{\mathrm{i}}(\varphi) \\
\theta_{\mathrm{i}}(\varphi) \\
M_{\mathrm{i}}(\varphi) \\
N_{\mathrm{i}}(\varphi) \\
V_{\mathrm{i}}(\varphi) \\
\cdots \\
1
\end{array}\right]
$$

In Eq. (33), $u, v, \theta, M, N$, and $V$ denote the radial displacement, the tangential displacement, the crosssectional rotation, the bending moment, the normal force, and the shear force. The vector on the left-hand side of Eq. (33) refers to an arbitrary cross-section, defined by the angular coordinate $\varphi$. It is the product of the transfer matrix and the vector on the right-hand side of Eq. (33). The complete list of the nonzero elements of the transfer matrix $T_{i j}(\varphi)$ is available in Ref. [65]. Notably, the sixby-six submatrix located at the top-left zone of this matrix represents the solutions for an unloaded part of the segmental tunnel ring [65]. The top-right six-by-one column vector of this matrix stands for the superposition of solutions for generalized loads, referred to as "load integrals" (superscript " $L$ "). Load integrals for dead load, point loads, and for interfacial discontinuities of kinematic variables are given in Ref. [65]. Those for a uniform temperature change are given in Ref. [73], the ones for the ground pressure in Ref. [57], and those for the overload on the ground surface in Ref. [74]. The vector on the right-hand side of Eq. (33) contains the static and kinematic variables at the initial cross-section (index "i"). They can be determined from the boundary conditions [65].

In the present paper, structural analysis of the segmental tunnel ring was based on the nonlinear hybrid method developed by Zhang et al. [64]. It is characterized by a combination of measurements and analytical or numerical structural analyses. In the present context, the measured interfacial displacement discontinuities, together with prescribed point loads, serve as input for structural analysis. The nonlinearity of the analyses is the consequence of consideration of tensile cracking of the segments. This involves the four approaches, i.e., the $f i b$ code, the JSCE code, the GB50010 code, and the multiscale model for the description of tensile softening of concrete. It results in four modes of nonlinear hybrid structural analyses. They follow the same strategy, as will be described subsequently.

Structural analysis consists of two load cases [64]. As for Load case I, non-zero point loads are considered, whereas the relative rotations at the joints are set equal to zero. Results from this load case are the deformations, the internal forces, and, if occurring, cracks of the segments caused by large point loads. This requires consideration of the tensile softening of concrete. Load case II is concerned with the relative rotations at the joints, resulting in rigid-body displacements of the tunnel ring. These rotations are quantified with the help of the measured displacement discontinuities at the joints, whereas the point loads are set equal to zero. The described quantification starts with estimates at the local scale of the joints, based on the Bernoulli-Euler hypothesis. It is further improved at the global scale of the entire ring such that the estimates result in rigid-body displacements of the segments. Notably, herein a symmetric mode of rigid-body displacements is considered. This is motivated by the fact that the experimentally observed structural behavior has turned out to be close to symmetric [52]. In case of asymmetric deformations of segmental tunnel rings, two additional antisymmetric modes of rigid-body displacements must be considered [75]. Superposition of the displacements obtained from the two load cases yields the deformational answer of the structure. Although the material behavior is nonlinear in load case I, this superposition is admissible because of the following reasons: (i) Load case II results only in rigid-body displacements of segments, and (ii) the formulation of the equilibrium equations is independent of the deformations [64].

In order to assess the added value resulting from combining structural analysis of segmental tunnel rings with multi-scale modeling of concrete, it is necessary to compare the results from multi-scale structural analysis and those from conventional structural analysis, based on the $f i b$ code, the JSCE code, and the GB50010 code, with the experimental data. Such a comparison is focused on (i) the convergences, which are relevant to the serviceability of tunnel linings, and on (ii) crack openings of concrete, relevant to the durability of the structure.

The horizontal and vertical convergences, predicted by the four modes of structural analysis, agree well with those measured in the experiment (see Fig. 12). This agreement underlines the usefulness of all of the four modes of structural analysis. As far as the convergences of the segmental tunnel ring are concerned, the added value of multi-scale modeling of concrete is insignificant. 
This is consistent with what has been found in the work of Zhang et al. [69]. This is because rigid-body displacements of segments dominate the convergences, whereas the deformations of the segments have little influence on them [64]. Notably, different approaches for the description of the tensile strength and of softening of concrete exhibit influence only on the deformations of the segments, but not on their rigid-body displacements.

As for the cracking of the concrete, the comparison starts with the onset of cracking of segments. The first two modes of conventional structural analysis, associated with the fib code and the JSCE code, indicate that cracking started at $P_{1}$ equal to 0.181 and $0.149 \mathrm{MN}$, respectively, see the magenta circles in Figs. 13(a) and 13(b). These values are by $55 \%$ and $27 \%$, respectively, larger than the corresponding experimental value, i.e., $0.117 \mathrm{MN}$, marked by the green arrows in Fig. 13. Both the third mode of structural analysis, based on the GB50010 code, and multi-scale structural analysis indicate that cracking started as $P_{1}$ reached $0.117 \mathrm{MN}$, see the magenta circles in Figs. 13(c) and 13(d). Thus, both the GB50010 code and the multi-scale model are useful for the prediction of the onset of cracking, which is closely related to the tensile strength of the concrete.

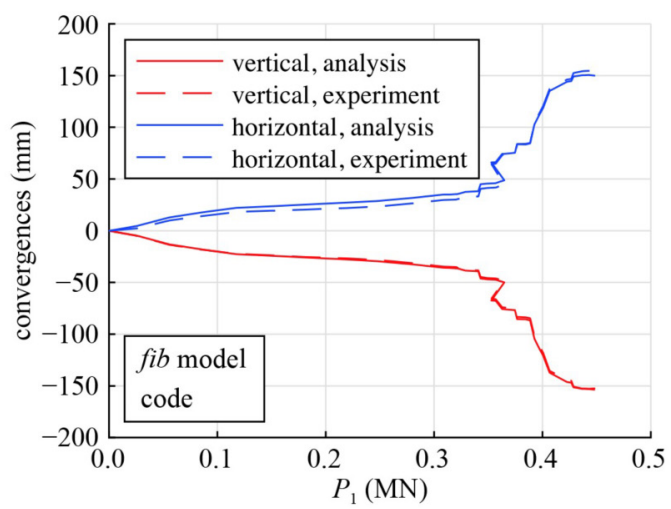

(a)

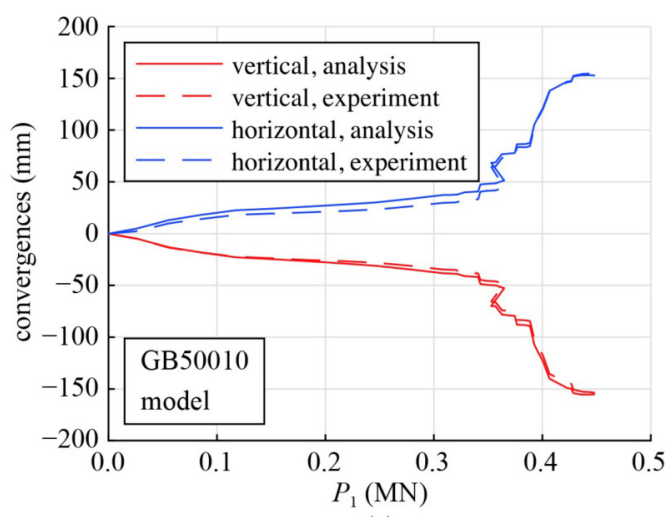

(c)
However, crack opening is mainly associated with the tensile softening of the concrete. This provides the motivation to compare also the crack openings, obtained by the third mode of conventional structural analysis, with the ones resulting from multi-scale structural analysis. Herein, two load levels are considered. Load level I, characterized by $P_{1}=0.3 \mathrm{MN}$, simulates the external loads imposed on the tunnel linings in the expected practical service [52]. The third mode of conventional structural analysis yields the maximum crack opening at the bottom region of the ring. Its value is approximately by a half larger than that obtained from multi-scale structural analysis, see the magenta squares in Figs. 13(c) and 13(d). Unfortunately, so far, the crack opening was not experimentally measured. However, it was measured at load level II, characterized by $P_{1}=0.448 \mathrm{MN}$. This value refers to the bearing capacity of the tunnel ring [52]. The experimentally obtained range of the maximum crack opening was marked by the green line segments in Figs. 13(c) and 13(d). The maximum crack opening, obtained from the third mode of conventional structural analysis, exceeds the experimentally obtained range, see the magenta triangle and the green line segment in Fig. 13(c). As for multi-

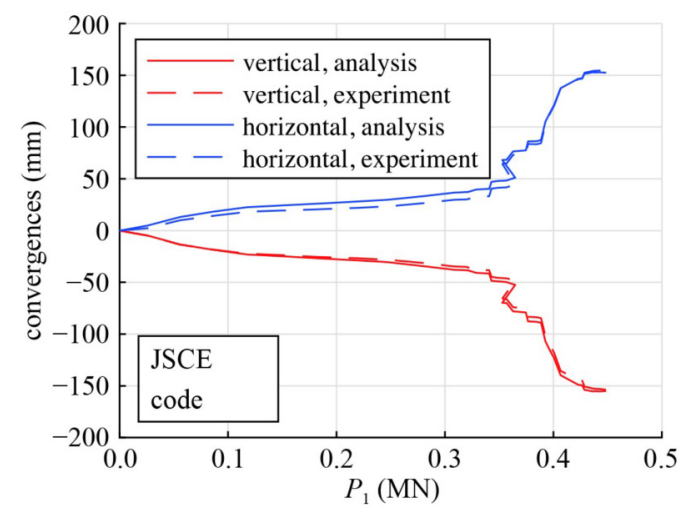

(b)

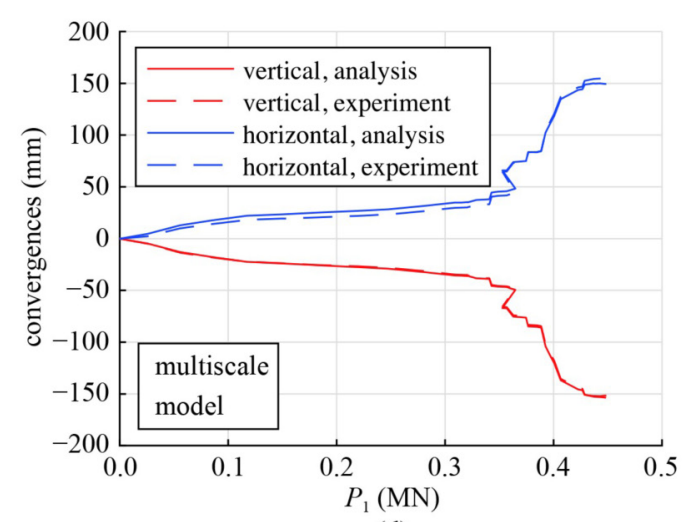

(d)

Fig. 12 Comparison of convergences obtained from experimental measurements with those from conventional structural analysis based on (a) the fib Model Code [66]; (b) the JSCE Guidelines for Concrete [67]; (c) the GB50010-2010 [68]; and from (d) multi-scale structural analysis. 
scale structural analysis, however, the maximum crack opening is in the experimentally obtained range, see the magenta triangle and the green line segment in Fig. 13(d). This leads to the conclusion that multi-scale structural analysis enables more realistic predictions of both the onset of cracking and the evaluation of the crack opening, as compared to the three modes of conventional structural analysis. Therefore, the added value of multi-scale modeling of concrete is significant for an elaborate design of segmental tunnel rings, particularly for their long-term durability.

4.5 Discussions of the trade-off between the number of fitting parameters and the prediction quality

Four approaches for the determination of the tensile

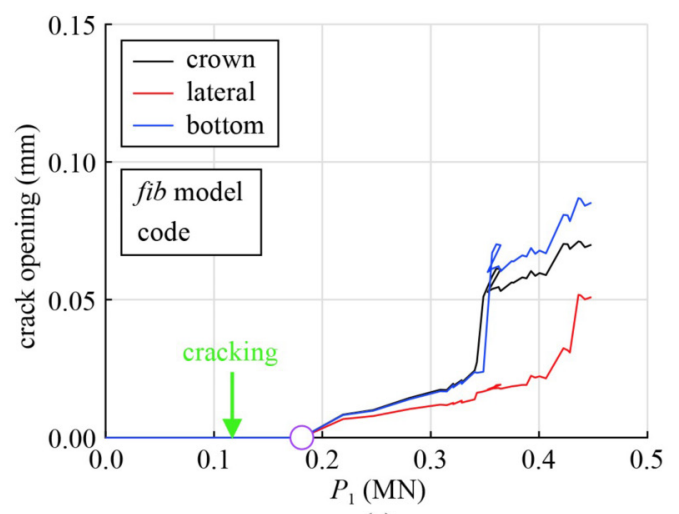

(a)

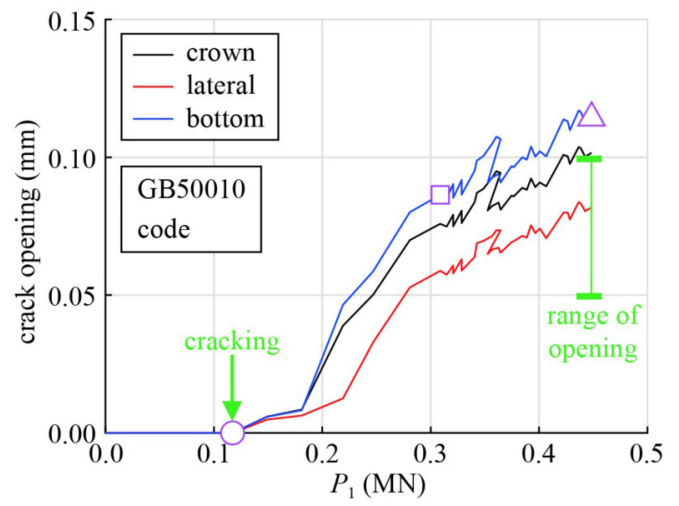

(c) strength and of softening of concrete were considered in this work, see Table 6 for a summary of their input and prediction quality. The $f i b$ code and the JSCE code use the experimentally determined compressive strength as input. As regards the GB50010 code and the multi-scale model, efforts concerning material tests are superfluous. Input for the GB50010 code refers to the strength grade of the concrete, usually provided by structural designers. Thus, a material law from a code of practice is designed for entire classes of concrete, no matter whether or not the binder contains supplementary cementitious materials. In case of the multi-scale model, the input refers to the initial composition of the concrete, characterized by the customized mix design, and the maturity of the material, typically quantified by means of hydration degrees. Therefore, the multi-scale model provides a material law,

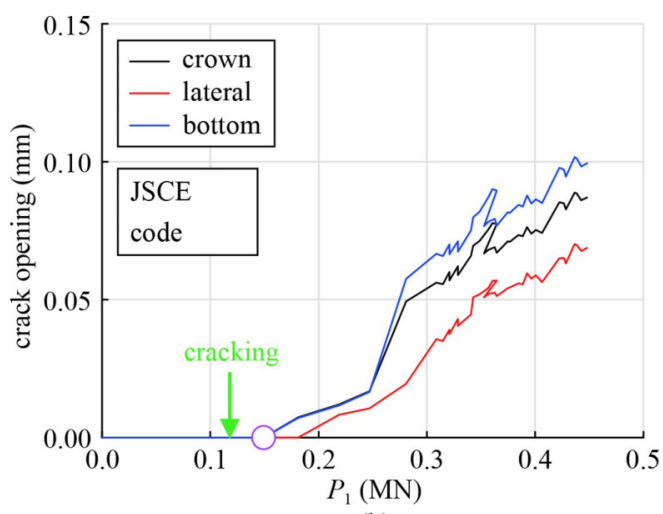

(b)

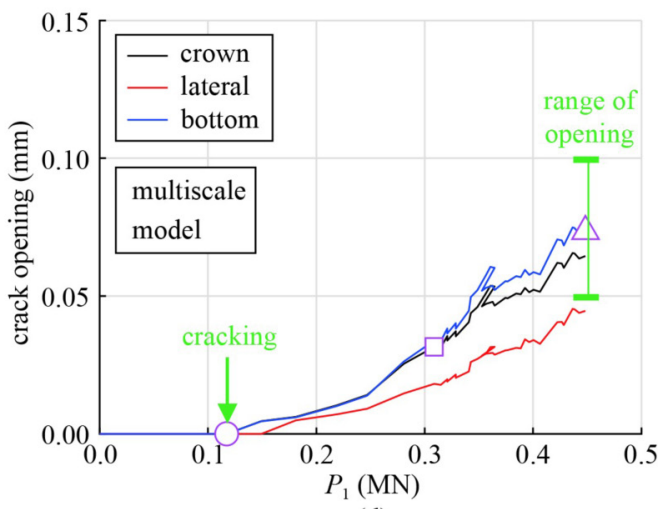

(d)

Fig. 13 Development of bending-induced crack openings at the segment surface, obtained from conventional structural analysis by means of (a) the fib Model Code [66]; (b) the JSCE Guidelines for Concrete [67]; (c) the GB50010-2010 [68], and from (d) multi-scale structural analysis; the green arrows point to $P_{1}=0.117 \mathrm{MN}$, corresponding to the experimentally-observed onset of cracking; the line segments in green color represent the experimentally measured range of the maximum crack opening.

Table 6 Input for different approaches for determination of the tensile strength and of softening of concrete, and prediction quality of the corresponding structural analyses

\begin{tabular}{lcccc}
\hline content of comparison & $f i b$ code & JSCE code & GB50010 code & multi-scale model \\
\hline input & $f_{\mathrm{c}}$ & $f_{\mathrm{c}}$ & strength grade & composition and maturity of concrete \\
prediction of crack initiation & overestimation by 55\% & overestimation by 27\% & reliable & reliable \\
prediction of crack opening & - & - & overestimation & reliable \\
\hline
\end{tabular}


customized for a specific concrete of interest, accounting for the initial composition and the maturity of concrete. This is an important added value of the multi-scale model relative to the codes of practice. When it comes to the prediction quality of structural analyses, the $f i b$ code and the JSCE code overestimate the external loading corresponding to the onset of cracking by $55 \%$ and $27 \%$, respectively. An assessment of the predicted crack opening is pointless. Both the GB50010 code and the multi-scale model are reliable for the prediction of crack initiation. The GB50010 code, however, results in a larger crack opening as compared to the one determined by the multi-scale model. The latter also allows for a reliable prediction of the crack opening at the stage of the bearing capacity of the tunnel ring. Thus, concerning an economical design of segmental tunnel rings, multi-scale structural analysis is useful, because it allows for an elaborate description of the crack opening. Nevertheless, the larger the crack openings, the higher the risk of the durability of the structure will be. In this regard, the GB50010 code delivers a more conservative result of an assessment of the durability of the structure. If implementation of multi-scale structural analysis presents a problem to engineers, it is good to know that conventional structural analysis, based on the GB50010 code, is still a useful alternative.

\subsection{Conclusions}

Concerning the investigated tunnel ring, the following conclusions are drawn.

1) As far as the convergences are concerned, the approach for determination of the tensile strength and of softening of concrete is of minor importance, because these quantities are governed by rigid-body displacements of the segments.

2) As regards the prediction of the onset of cracking, both the GB50010 code and the multi-scale model are reliable.

3) Concerning a durability assessment of segmental tunnel linings, the multi-scale model delivers a more realistic prediction of the crack opening than the GB50010 code. The latter is still a useful alternative for engineers, familiar with simple formulae for calculations, because it results in a more conservative durability assessment.

\section{Summary of the conclusions from the three examples}

Based on the results from the three examples reviewed in this paper, it is concluded that multi-scale models do indeed have a significant added value, albeit not necessarily of the same degree.

1) The first example refers to a particularly challenging research area, because the microscopic mechanisms, governing the complex macroscopic behavior, are still not fully deciphered. Multi-scale models provide the added value of establishing a quantitative link between a specific microscopic mechanism of interest and the related macroscopic behavior. Even if a specific multiscale approach does not completely solve a problem within this research area, it nonetheless provides a valuable contribution to an ongoing international scientific discussion.

2) Moreover, in the context of the first example it was shown that multi-scale models based on physically interpretable input parameters allow for genuine mechanical predictions by the analysis models. Model predictions represent an added value compared to the demonstration of the performance of a model after optimization of its input parameters to reproduce the experimentally observed mechanical behavior.

3) As for the second example, it is well known that the thermal expansion coefficient of the cement paste changes with the internal $R H$. It is concluded that bottomup homogenization to the material scale of concrete renders available microscopic information exploitable in the framework of macroscopic structural analysis. This is useful for structural engineers who need realistic input values for macroscopic structural simulations.

4) Moreover, in the second example, it was shown that top-down quantification of microstresses of the constituents of concrete provides valuable insight into stress fluctuations at the microstructure of concrete. Even though different relative humidities only result in small macroscopic stress fluctuations of heated concrete plates, the magnitudes of microstructural stress fluctuations are significant. This is relevant to an assessment of the risk of microcracking of concrete. Consequently, it is important for the durability of pavements.

5) In the third example, it was demonstrated that multiscale models have the potential of providing material laws, customized for a specific concrete of interest, accounting for its initial composition and its maturity. This is an important added value relative to the alternative of employing a material law from a code of practice, designed for entire classes of concrete.

6) Moreover, in the framework of the third example, it was shown that customized multi-scale material laws can further increase the reliability of macroscopic structural simulations. This is particularly valuable provided that the computed quantities of interest are relevant to the durability of the analyzed engineering structure, such as e.g., crack opening displacements in segments of tunnel linings.

Based on the three representative examples reviewed in this work, it is concluded that multi-scale modeling frequently has an added value. However, its extent must be scrutinized and assessed on a case-by-case basis. Such 
an assessment should ideally include predictions by multi-scale models, the output from competing macroscopic models, and experimental data.

Acknowledgements Financial support by the Ministry of Science and Technology of China (No. 2021YFE0114100) and by the Federal Ministry of Education, Science and Research (BMBWF) of Austria (No. CN $11 / 2021$ ), jointly provided for the project "Intense Upgrades of the New Austrian Tunnelling Method (NATM) and Demonstration of its Applicability to High-Quality Urban Development", is gratefully acknowledged. In addition, the authors are indebted to the National Natural Science Foundation of China (Grant Nos. 51908424, U1934210) and the Shanghai Pujiang Program (Nos. 19PJ1409700, 20PJ1406100) for financial support of this work.

Open Access This article is licensed under a Creative Commons Attribution 4.0 International License (https://creativecommons.org/licenses/ by/4.0/), which permits use, sharing, adaptation, distribution and reproduction in any medium or format, as long as you give appropriate credit to the original author(s) and the source, provide a link to the Creative Commons licence, and indicate if changes were made. The images or other third party material in this article are included in the article's Creative Commons licence, unless indicated otherwise in a credit line to the material. If material is not included in the article's Creative Commons licence and your intended use is not permitted by statutory regulation or exceeds the permitted use, you will need to obtain permission directly from the copyright holder. To view a copy of this licence, visit http://creativecommons. org/licenses/by/4.0/.

\section{Notations}

$a$ : thermal diffusivity

$B_{j}$ : fitting parameter introduced by Li et al. [29]; $j \in[1,2,3,4,5]$

$C$ : fitting parameter introduced by Tang et al. [26]

$D$ : fitting parameter introduced by Tang et al. [26]

$D I F$ : dynamic increase factor

$D I F_{\text {exp }}$ : dynamic increase factor determined by experiments

$D I F_{\text {mod }}:$ dynamic increase factor determined by modeling

$d$ : diameter of cylindrical specimens

$d_{\text {max }}:$ maximum size of the aggregates

$d_{1}$ : damage parameter

$f_{\mathrm{p}}$ : volume fraction of phase $p$

$f_{\text {sta: }}$ : stress obtained from quasi-static tests

$f_{\text {ult }}$ : ultimate stress obtained from high-dynamic tests

$E$ : Young's modulus

$E_{\mathrm{d}}$ : elastic stiffness of concrete during softening

$G$ : fracture energy

$H$ : width of tunnel segments

$h$ : thickness of the pavement plate

$M$ : bending moment

$M^{\mathrm{L}}$ : load integral for the bending moment

$M_{\mathrm{i}}$ : bending moment at the initial cross-section

$N$ : normal force

$N^{\mathrm{L}}$ : load integral for the normal force

$N_{\mathrm{i}}$ : normal force at the initial cross-section $n$ : number of individual tests in one series

$P_{1}$ : point load acting in the top and the bottom regions of the segmental tunnel ring

$P_{2}$ : point load acting in the lateral regions of the segmental tunnel ring

$P_{3}$ : point load acting in the intermediate regions between $P_{1}$ and $P_{2}$

$R$ : radius of the axis of the segmental tunnel ring

$S$ : fitting parameter introduced by Gebbeken and Greulich [27]

$S_{i}$ : steps of temperature increment

SSE: sum of squared errors

$T$ : temperature

$T_{i j}$ : element of the transfer matrix

$T_{\text {ref }}:$ reference temperature

$\Delta T$ : temperature change

$\Delta T^{\text {top: }}$ temperature change at the top surface

$\Delta T_{\text {fin }}^{\text {top }}$ : maximum increase of the temperature at the top surface

$\Delta T_{i}^{\text {top: }}$ temperature increment at time step $t_{i}$

$t$ : time

$t_{i}:$ time step

$u$ : radial component of the displacement

$u^{\mathrm{L}}$ : load integral for the radial displacement

$u_{\mathrm{i}}$ : radial component of the displacement at the initial crosssection

$u_{0}, w_{0}$ : displacement components in the $x$ - and the $y$-direction

$v_{i}$ : tangential component of the displacement at the initial crosssection

$V$ : shear force

$V^{\mathrm{L}}$ : load integral for the shear force

$V_{\mathrm{i}}$ : shear force at the initial cross-section

$W_{x}$ : fitting parameter introduced by Gebbeken and Greulich [27]

$W_{y}$ : fitting parameter introduced by Gebbeken and Greulich [27]

$w$ : crack width

$x, y, z$ : Cartesian coordinate

$\alpha$ : thermal expansion coefficient

$E_{\text {hom }}$ : macroscopic strain tensor

$\varepsilon$ : strain

$\varepsilon_{\mathrm{p}}$ : strain tensor of phase $p$

$\varepsilon_{x x}$ : normal strain in the $x$-direction

$\varepsilon_{\mathrm{p}}^{\mathrm{e}}$ : eigenstrain of phase $p$

$\varepsilon_{0}^{\mathrm{e}}$ : eigenstretch

$\varepsilon_{\mathrm{dis}}^{\mathrm{e}}:$ eigendistortion

$\ell$ : axial length of cylindrical specimens

$\kappa_{0}^{e}$ : eigencurvature

$\sigma:$ stress

$\rho$ : mass density

$\theta$ : cross-sectional rotation

$\theta^{\mathrm{L}}$ : load integral for the cross-sectional rotation

$\theta_{\mathrm{i}}:$ rotation of the initial cross-section

$\xi$ : fitting parameter related to the activation, used by Brara and Klepaczko [28]

$\mathbb{A}_{p}:$ strain concentration tensor of phase $p$

$\mathbb{C}_{p}$ : stiffness tensor of phase $p$

$\mathbb{D}_{p q}$ : eigenstrain influence tensor

I: symmetric fourth-order unity tensor 
$\mathbb{S}$ : Eshelby tensor

\section{References}

1. Geers M G D, Kouznetsova V G, Brekelmans W A M. Multi-scale computational homogenization: Trends and challenges. Journal of Computational and Applied Mathematics, 2010, 234(7): 2175-2182

2. Wriggers $\mathrm{P}$, Moftah S O. Mesoscale models for concrete: Homogenisation and damage behavior. Finite Elements in Analysis and Design, 2006, 42(7): 623-636

3. Oskay C, Fish J. Eigendeformation-based reduced order homogenization for failure analysis of heterogeneous materials. Computer Methods in Applied Mechanics and Engineering, 2007, 196(7): 1216-1243

4. Moulinec H, Suquet P. A numerical method for computing the overall response of nonlinear composites with complex microstructure. Computer Methods in Applied Mechanics and Engineering, 1998, 157(1-2): 69-94

5. Zaoui A. Continuum micromechanics: Survey. Journal of Engineering Mechanics, 2002, 128(8): 808-816

6. Auriault J L. Heterogeneous medium. Is an equivalent macroscopic description possible? International Journal of Engineering Science, 1991, 29(7): 785-795

7. Popper K. Conjectures and Refutations: The Growth of Scientific Knowledge. London: Routledge, 2014

8. Zhang Y, Pichler C, Yuan Y, Zeiml M, Lackner R. Micromechanics-based multifield framework for early-age concrete. Engineering Structures, 2013, 47: 16-24

9. Irfan-ul-Hassan M, Pichler B, Reihsner R, Hellmich C. Elastic and creep properties of young cement paste, as determined from hourly repeated minute-long quasi-static tests. Cement and Concrete Research, 2016, 82: 36-49

10. Pichler B, Scheiner S, Hellmich C. From micron-sized needleshaped hydrates to meter-sized shotcrete tunnel shells: Micromechanical upscaling of stiffness and strength of hydrating shotcrete. Acta Geotechnica, 2008, 3(4): 273-294

11. Ullah S, Pichler B, Scheiner S, Hellmich C. Influence of shotcrete composition on load-level estimation in NATM - tunnel shells: Micromechanics-based sensitivity analyses. International Journal for Numerical and Analytical Methods in Geomechanics, 2012, 36(9): 1151-1180

12. Fischer I, Pichler B, Lach E, Terner C, Barraud E, Britz F. Compressive strength of cement paste as a function of loading rate: Experiments and engineering mechanics analysis. Cement and Concrete Research, 2014, 58: 186-200

13. Binder E, Reihsner R, Yuan Y, Mang H A, Pichler B L A. Highdynamic compressive and tensile strength of specimens made of cementitious materials. Cement and Concrete Research, 2020, 129: 105890

14. Hlobil M. Micromechanical analysis of blended cement-based composites. Dissertation for the Doctoral Degree. Vienna: Tu Wien and Prague: Czech Technical University, 2016

15. Kühn T, Steinke C, Sile Z, Zreid I, Kaliske M, Curbach M. Dynamic properties of concrete in experiment and simulation.
Concrete and Reinforced Concrete, 2016, 111(1): 41-50 (in German)

16. Zhang M, Wu H J, Li Q M, Huang F L. Further investigation on the dynamic compressive strength enhancement of concrete-like materials based on split Hopkinson pressure bar tests. Part I: Experiments. International Journal of Impact Engineering, 2009, 36(12): 1327-1334

17. Mihashi H, Wittmann F H. Stochastic approach to study the influence of rate of loading on strength of concrete. Heron, 1980, 25(3): 5-54

18. Bažant Z P, Caner F C, Adley M D, Akers S A. Fracturing rate effect and creep in microplane model for dynamics. Journal of Engineering Mechanics, 2000, 126(9): 962-970

19. Wang X F, Yang Z J, Yates J R, Jivkov A P, Zhang C. Monte Carlo simulations of mesoscale fracture modelling of concrete with random aggregates and pores. Construction \& Building Materials, 2015, 75: 35-45

20. Gary G, Bailly P. Behaviour of quasi-brittle material at high strain rate. Experiment and modelling. European Journal of Mechanics. A, Solids, 1998, 17(3): 403-420

21. Hao Y, Hao H, Li Z X. Influence of end friction confinement on impact tests of concrete material at high strain rate. International Journal of Impact Engineering, 2013, 60: 82-106

22. Flores-Johnson E A, Li Q M. Structural effects on compressive strength enhancement of concrete-like materials in a split Hopkinson pressure bar test. International Journal of Impact Engineering, 2017, 109: 408-418

23. Kühn T. Experimental fundamentals for the meso and macroscopic modeling of concrete at high loading velocities: A critical review of the strain rate effect. Dissertation for the Doctoral Degree. Dresden: Technische Universität Dresden, 2020

24. Lu D, Wang G, Du X, Wang Y. A nonlinear dynamic uniaxial strength criterion that considers the ultimate dynamic strength of concrete. International Journal of Impact Engineering, 2017, 103: 124-137

25. Zhou X Q, Hao H. Modelling of compressive behaviour of concrete-like materials at high strain rate. International Journal of Solids and Structures, 2008, 45(17): 4648-4661

26. Tang T, Malvern L E, Jenkins D A. Rate effects in uniaxial dynamic compression of concrete. Journal of Engineering Mechanics, 1992, 118(1): 108-124

27. Gebbeken N, Greulich S. A new material model for SFRC under high dynamic loadings. In: Proceedings of 11th International Symposium on Interaction of the Effects of Munitions with Structures (ISIEMS 2003). Mannheim: ISIEMS, 2003

28. Brara A, Klepaczko J R. Experimental characterization of concrete in dynamic tension. Mechanics of Materials, 2006, 38(3): 253-267

29. Li Q M, Lu Y B, Meng H. Further investigation on the dynamic compressive strength enhancement of concrete-like materials based on split hopkinson pressure bar tests. Part II: numerical simulations. International Journal of Impact Engineering, 2009, 36(12): 1335-1345

30. MATLAB. Version R2018. Natick, MA: MathWorks. 2018

31. Online Etymology Dictionary. Predict (v.). Available at the website of Online Etymology Dictionary. 2021

32. EN 1992-1-1. Eurocode 2: Design of Concrete Structures-Part 1- 
1: General Rules and Rules for Buildings. Brussels: European Committee for Standardization, 2011

33. Euro-International Committee for Concrete. CEB-FIP model code 1990: Design Code. London: Thomas Telford Publishing, 1993

34. National Cooperative Highway Research Program. Guide for Mechanistic-empirical Design of New and Rehabilitated Pavement Structures. Final Report NCHRP Project 1-37A. 2004

35. Huang H, An M, Wang Y, Yu Z, Ji W. Effect of environmental thermal fatigue on concrete performance based on mesostructural and microstructural analyses. Construction \& Building Materials, 2019, 207: 450-462

36. Chen D, Zou J, Zhao L, Xu S, Xiang T, Liu C. Degradation of dynamic elastic modulus of concrete under periodic temperaturehumidity action. Materials (Basel), 2020, 13(3): 611

37. An M, Huang H, Wang Y, Zhao G. Effect of thermal cycling on the properties of high-performance concrete: Microstructure and mechanism. Construction \& Building Materials, 2020, 243: 118310

38. Fu Y F, Wong Y L, Poon C S, Tang C, Lin P. Experimental study of micro/macro crack development and stress-strain relations of cement-based composite materials at elevated temperatures. Cement and Concrete Research, 2004, 34(5): 789-797

39. Pichler B, Hellmich C. Estimation of influence tensors for eigenstressed multiphase elastic media with nonaligned inclusion phases of arbitrary ellipsoidal shape. Journal of Engineering Mechanics, 2010, 136(8): 1043-1053

40. Emanuel J, Hulsey J. Prediction of the thermal coefficient of expansion of concrete. Journal of the American Concrete Institute, 1977, 74(4): 149-155

41. Wang H, Mang H, Yuan Y, Pichler B. Multiscale thermoelastic analysis of the thermal expansion coefficient and of microscopic thermal stresses of mature concrete. Materials (Basel), 2019, 12(17): 2689

42. EN 1992-1-1. Eurocode 2: Design of Concrete Structures-Part 11: General Rules and Rules for Buildings. Edition: 2015-07-31. Brussels: European Committee for Standardization, 2015

43. Wang H, Hellmich C, Mang H, Pichler B. May reversible water uptake/release by hydrates explain the thermal expansion of cement paste?-Arguments from an inverse multiscale analysis Cement and Concrete Research, 2018, 113: 13-26

44. Meyers S. Thermal expansion characteristics of hardened cement paste and of concrete. Highway Research Board Proceedings, 1951, 30: 193-203

45. Mitchell L J. Thermal expansion tests on aggregates, neat cements, and concretes. Proceedings of the American Society for Testing and Materials, 1953, 53: 963-977

46. Dettling H. Thermal expansion of cement pastes, aggregates, and concretes. Dissertation for the Doctoral Degree. Stuttgart: Technische Hochschule Stuttgart, 1962 (in German)

47. Wang H, Höller R, Aminbaghai M, Hellmich C, Yuan Y, Mang H, Pichler B. Concrete pavements subjected to hail showers: A semianalytical thermoelastic multiscale analysis. Engineering Structures, 2019, 200: 109677

48. Höller R, Aminbaghai M, Eberhardsteiner L, Eberhardsteiner J, Blab R, Pichler B, Hellmich C. Rigorous amendment of Vlasov's theory for thin elastic plates on elastic Winkler foundations, based on the Principle of Virtual Power. European Journal of Mechanics. A, Solids, 2019, 73: 449-482

49. Königsberger M, Pichler B, Hellmich C. Micromechanics of ITZaggregate interaction in concrete, part I: Stress concentration. Journal of the American Ceramic Society, 2014, 97(2): 535-542

50. Königsberger M, Pichler B, Hellmich C. Micromechanics of ITZaggregate interaction in concrete, part II: Strength upscaling. Journal of the American Ceramic Society, 2014, 97(2): 543-551

51. Wang H, Binder E, Mang H, Yuan Y, Pichler B. Multiscale structural analysis inspired by exceptional load cases concerning the immersed tunnel of the Hong Kong-Zhuhai-Macao Bridge. Underground Space, 2018, 3(4): 252-267

52. Liu X, Bai Y, Yuan Y, Mang H A. Experimental investigation of the ultimate bearing capacity of continuously jointed segmental tunnel linings. Structure and Infrastructure Engineering, 2016, 12(10): 1364-1379

53. Liu X, Jiang Z, Yuan Y, Mang H A. Experimental investigation of the ultimate bearing capacity of deformed segmental tunnel linings strengthened by epoxy-bonded steel plates. Structure and Infrastructure Engineering, 2018, 14(6): 685-700

54. Liu X, Jiang Z, Zhang L. Experimental investigation of the ultimate bearing capacity of deformed segmental tunnel linings strengthened by epoxy-bonded filament wound profiles. Structure and Infrastructure Engineering, 2017, 13(10): 1268-1283

55. Zhang J L, Liu X, Ren T Y, Yuan Y, Mang H A. Structural behavior of reinforced concrete segments of tunnel linings strengthened by a steel-concrete composite. Composites. Part B, Engineering, 2019, 178: 107444

56. Liu X, Zhang J L, Jiang Z, Liu Z, Xu P, Li F. Experimental investigations of a segmental tunnel ring strengthened by using ultra-high performance concrete (UHPC). China Journal of Highway Transport, 2021, 34(8): 181-190 (in Chinese)

57. Zhang J L, Schlappal T, Yuan Y, Mang H A, Pichler B. The influence of interfacial joints on the structural behavior of segmental tunnel rings subjected to ground pressure. Tunnelling and Underground Space Technology, 2019, 84: 538-556

58. Galván A, Peña F, Moreno-Martínez J Y. Effect of TBM advance in the structural response of segmental tunnel lining. International Journal of Geomechanics, 2017, 17(9): 04017056

59. Do N A, Dias D, Oreste P, Djeran-Maigre I. Three-dimensional numerical simulation for mechanized tunnelling in soft ground: The influence of the joint pattern. Acta Geotechnica, 2014, 9(4): 673-694

60. Wang Z, Wang L, Li L, Wang J. Failure mechanism of tunnel lining joints and bolts with uneven longitudinal ground settlement. Tunnelling and Underground Space Technology, 2014, 40: 300-308

61. Liu X, Dong Z, Bai Y, Zhu Y. Investigation of the structural effect induced by stagger joints in segmental tunnel linings: First results from full-scale ring tests. Tunnelling and Underground Space Technology, 2017, 66: 1-18

62. Liu X, Dong Z, Song W, Bai Y. Investigation of the structural effect induced by stagger joints in segmental tunnel linings: Direct insight from mechanical behaviors of longitudinal and circumferential joints. Tunnelling and Underground Space Technology, 2018, 71: 271-291 
63. Liu X, Zhang Y M, Bao Y H. Full-scale experimental investigation on stagger effect of segmental tunnel linings. Tunnelling and Underground Space Technology, 2020, 102: 103423

64. Zhang J L, Mang H A, Liu X, Yuan Y, Pichler B. On a nonlinear hybrid method for multiscale analysis of a bearing capacity test on a real-scale segmental tunnel ring. International Journal for Numerical and Analytical Methods in Geomechanics, 2019, 43(7): 1343-1372

65. Zhang J L, Vida C, Yuan Y, Hellmich C, Mang H A, Pichler B. A hybrid analysis method for displacement-monitored segmented circular tunnel rings. Engineering Structures, 2017, 148: 839-856

66. International Federation for Structural Concrete. Fib Model Code for Concrete Structures 2010. Berlin: Ernst \& Sohn, 2010

67. Japan Society of Civil Engineering (JSCE). Standard Specifications for Concrete Structures-2007 "Design". Tokyo: JSCE, 2010

68. GB50010-2010. Chinese Code for Design of Concrete Structures. Beijing: Ministry of Housing and Urban-Rural Development of China, General Administration of Quality Supervision, Inspection and Quarantine of China, 2010

69. Zhang J L, Binder E, Liu X, Yuan Y, Mang H A, Pichler B L A. Assessment of the added value of multiscale modeling of concrete for structural analysis of segmental tunnel rings. Encyclopedia of Materials: Composites, 2021, 3: 69-78
70. Königsberger M, Hlobil M, Delsaute B, Staquet S, Hellmich C, Pichler B. Hydrate failure in ITZ governs concrete strength: A micro-to-macro validated engineering mechanics model. Cement and Concrete Research, 2018, 103: 77-94

71. Hill R. Continuum micro-mechanics of elastoplastic polycrystals. Journal of the Mechanics and Physics of Solids, 1965, 13(2): 89-101

72. Zhang J L, Liu X, Yuan Y, Mang H A, Pichler B L A. Transfer relations: useful basis for computer-aided engineering of circular arch structures. Engineering Computations, 2021, 38(3): 1287-1302

73. Zhang J L, Hellmich C, Mang H A, Yuan Y, Pichler B. Application of transfer relations to structural analysis of arch bridges. Computer Assisted Methods in Engineering and Science, 2018, 24: 199-215

74. Zhang J L, Liu X, Zhao J B, Yuan Y, Mang H A. Application of a combined precast and in-situ-cast construction method for largespan underground vaults. Tunnelling and Underground Space Technology, 2021, 111: 103795

75. Jiang Z, Liu X, Schlappal T, Zhang J L, Mang H, Pichler B L A. Asymmetric serviceability limit states of symmetrically loaded segmental tunnel rings: Hybrid analysis of real-scale tests. Tunnelling and Underground Space Technology, 2021, 113: 103832 